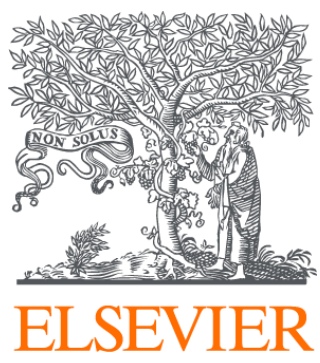

Since January 2020 Elsevier has created a COVID-19 resource centre with free information in English and Mandarin on the novel coronavirus COVID-

19. The COVID-19 resource centre is hosted on Elsevier Connect, the company's public news and information website.

Elsevier hereby grants permission to make all its COVID-19-related research that is available on the COVID-19 resource centre - including this research content - immediately available in PubMed Central and other publicly funded repositories, such as the WHO COVID database with rights for unrestricted research re-use and analyses in any form or by any means with acknowledgement of the original source. These permissions are granted for free by Elsevier for as long as the COVID-19 resource centre remains active. 


\title{
The influence of the COVID-19 pandemic on the hedging functionality of Chinese financial markets
}

\author{
Shaen Corbet ${ }^{\mathrm{a}, \mathrm{b}}$, Yang (Greg) Hou ${ }^{\mathrm{b}}$, Yang Hu ${ }^{\mathrm{b}}{ }^{*}$, Les Oxley ${ }^{\mathrm{b}}$ \\ ${ }^{\text {a }}$ DCU Business School, Dublin City University, Dublin 9, Ireland \\ ${ }^{\mathrm{b}}$ School of Accounting, Finance and Economics, University of Waikato, New Zealand
}

\section{A R T I C L E I N F O}

\section{Keywords:}

COVID-19

Hedge ratios

China

Financial markets

Diversification

\begin{abstract}
A B S T R A C T
In this paper, we investigate both constant and time-varying hedge ratios in terms of the effectiveness of CSI300 index futures during the COVID-19 crisis. Using naïve, OLS and EC/ROLS strategies to estimate constant hedge ratios, results indicate that the CSI300 spot index presents decreased effectiveness using the naïve hedging strategy; however, increased effectiveness of OLS and EC hedge ratios are identified. Differential behaviour is identified when considering five newly introduced COVID-19 concept-based stock indices. Time-varying hedge ratios indicate the weakened effectiveness, ranging between $20 \%$ and $40 \%$ variance reduction. Evidence suggests that the capability of the CSI300 index futures to hedge against the risks of the COVID-19 is impaired, regardless of whether constant or time-varying hedge ratios are used. Such results provide important implications to both local and foreign investors in the Chinese stock market.
\end{abstract}

\section{Introduction}

The COVID-19 pandemic has generated interesting questions surrounding whether stock index futures contracts can deliver effective hedging functionality against pandemic-related risks, particularly in China due to early origin effects. Effectively answering this question is important as not only was China the earliest epicentre of the COVID-19 pandemic, leading to long-range social and economic impacts on the local ecosystem, but also a substantial influence upon the pricing dynamics of domestic equity, energy, and commodity markets in both the short- and long-term (Corbet, Hou, Hu, and Oxley, 2020). We specifically utilise the China Securities Index 300 (CSI300 hereafter) stock index futures, as it was the first futures exchange introduced in China for both domestic and qualifying foreign investors. Specifically, it is unclear whether CSI300 index futures are capable of effectively hedging the risk of the underlying stock market after the pandemic began. Prior studies have suggested that the CSI300 stock index futures are effective in providing a direct hedge over the CSI300 spot index across a variety of hedging strategies (Hou and Li, 2013; Wei et al., 2011; Qu et al., 2019). We specifically consider how the index futures perform in both direct and cross-hedging scenarios during the COVID-19 pandemic.

Furthermore, several sector stock portfolios have been established in China by local financial data providers. These stock portfolios consist of several COVID-19-related public firms that operate businesses directly combating COVID-19, such as facemask production, virus testing, vaccination research, influenza-related medicine production, and the development and production of disinfectant technology (Corbet, Hou, Hu, Oxley, and Xu, 2020). We explore whether Chinese stock index futures offer improved cross-hedging

\footnotetext{
* Corresponding author.

E-mail address: yang.hu@waikato.ac.nz (Y. Hu).
} 
performance against such COVID-19 Chinese concept-based stock indices, providing important evidence as to how efficient the Chinese stock index futures are when mitigating the effects of market turmoil developed by the COVID-19 pandemic. To complete such analysis, we develop constant hedging strategies including naïve, Ordinary Least Squares (OLS) and Error Correction (EC)/ Revised OLS (ROLS) hedging mechanisms. The selected time-varying hedging strategies are based on the bivariate generalised autoregressive conditional heteroscedasticity (GARCH) with the specifications of constant conditional correlation (CCC), dynamic conditional correlation (DCC) and asymmetric DCC (ADCC) methodologies. Specifically, with the utilisation of these strategies, we construct direct hedging portfolios against the CSI300 spot index and cross-hedging portfolios against five COVID-19 concept-based stock indices including coronavirus, influenza, facemask, coronavirus detection and disinfectant, by using the CSI300 stock index futures. Hedging effectiveness, in light of variance reduction, is assessed for constant and time-varying strategies and compared against each other. We examine whether hedging effectiveness differs between the pre-and post-COVID-19 periods while examining the optimal strategy in both pre-crisis and crisis periods, the results of which are indicative of the effect of COVID-19 on the optimal level of cross-hedging. The effect of transaction costs on hedging effectiveness is also investigated.

Results indicate that the COVID-19 period enhances estimated hedging effectiveness for two of the three constant hedging strategies (OLS and EC). Concerning constant cross-hedging within the COVID-19 concept-based stock indices, variance reduction falls from approximately $49 \%$ to $61 \%$ in the pre-COVID- 19 period to a range between $11 \%$ and $45 \%$ as the COVID-19 pandemic begins. In contrast, time-varying direct hedging based on the CSI300 spot index experiences a reduction in hedging effectiveness between the preto post-COVID-19 periods. Time-varying cross-hedging over the COVID-19-related stock index portfolios falls, where almost 20\% to $40 \%$ of variance reduction is lost in the post-COVID-19 period. The results of the time-varying hedging strategies hold even when transaction costs are estimated using daily adjustments of hedge ratios.

The remainder of the paper is structured as follows. Section 2 presents a brief review of the relevant prior literature. The data and methodology used in the paper are presented in Sections 3 and 4, respectively. Section 5 presents empirical results and a discussions. Section 6 presents concluding comments.

\section{Previous literature}

The hedging risk of underlying spot assets constitutes one of the fundamental functions of a futures contract. For decades, the literature has explored several assumed optimal hedging strategies, particularly those using futures. Originating from Johnson (1976) and Stein (1976), a minimum variance (MV) hedging strategy is proposed such that an optimal futures position is pursued to minimise the variance of a hedging portfolio consisting of spot assets and futures contract. The optimal position in the futures contract is referred to as a minimum variance hedge ratio which is assumed to be constant. Ederington (1979) proposed an ordinary least squares (OLS) regression method to obtain a constant MV hedge ratio and recommended a reduction in the variance of the hedging portfolio compared to that of an un-hedged case, as a measure of hedging effectiveness. The OLS hedging strategy has been adopted in a set of prior studies (Hill and Schneeweis, 1982; Benet, 1992; Malliaris et al., 1991; Chen et al., 2004; Lien and Shrestha, 2007). However, an issue based on the underestimation of a constant MV hedge ratio can be identified, since the cointegration of the spot and futures prices is not considered in the OLS hedging strategy (Hill and Schneeweis, 1981; Cecchetti et al., 1988; da Hsiang, 1996). To resolve this issue, an error correction model that addresses both the long-run equilibrium and the short-run dynamics between spot and futures prices has been proposed for the derivation of a constant MV hedge ratio, which is found to provide better performance than the OLS strategy (Ghosh, 1993, 1995; Ghosh and Clayton, 1996). In addition, alternative constant optimal hedge ratios have been explored in other studies. More complexities are involved in the procedure of generating hedge ratios that aim to either maximise a hedger's expected utility or minimise the downside risk of the hedging portfolio. Typical processes include the mean-Gini coefficient hedging strategy (Chen et al., 2004), the generalised semi-variance hedging strategy (Lien and Tse, 2002), the lower partial moment (LPM) methodology (Demirer and Lien, 2003), the minimum value at risk (VaR) and conditional value at risk (CVaR) hedging strategy (Harris and Shen, 2006; Cao et al., 2010), a partial equilibrium model accounting for skewness in the hedger's utility function (Gilbert et al., 2006), and a generalised utility-based framework addressing higher-order moments of joint return distribution (Brooks et al., 2012).

Constant MV hedging ratios have been questioned in the literature. The conventional methods to derive constant MV ratios are underpinned by a ratio of covariance between the hedged asset and futures returns over the variance of futures itself. The literature identifies that the variance-covariance matrix of financial time series can exhibit time variations conditioned on the past information set, constituting the dynamic nature of joint return distribution (Engle, 1982, 2002; Bollerslev, 1986, 1990; Engle and Kroner, 1995). Ignoring the dynamics of second moments of the return distribution in the estimation processes of the MV hedge ratios may lead to sub-optimal decisions, especially in periods of high basis volatility. Time-varying MV hedge ratios have been proposed as an alternative approach by assuming a bivariate generalised autoregressive conditional heteroscedasticity (BGARCH) model, which suggests adjustments of the hedge ratios regularly to capture updated market conditions ${ }^{1}$ (Kroner and Sultan, 1993; Bera et al., 1997; Brooks et al.,

\footnotetext{
1 Compared to the traditional BGARCH models for hedging strategies, realised measures of the second moments of the return distribution have been used to explore effectiveness. Lai and Sheu (2010) incorporate the realised variance into the DCC GARCH model for hedging over the S\&P500 index, identifying improved performance from their modified methodological structure. Markopoulou et al. (2016) suggest a process of utilising realised variances and covariances of the hedged assets and futures returns and find improvements in hedging performance. Furthermore, other efforts to modify the modelling of time-varying hedge ratios for better performance include the incorporation of marginal skewness and joint excess kurtosis parameters in the estimation of the BGARCH hedge ratios (Hou and Holmes, 2020) and an alternative non-parametric estimation approach (Fan et al., 2016).
} 
2002; Cotter and Hanly, 2006; Baillie et al., 2007; Park and Jei, 2010; Fan et al., 2014; Kim and Park, 2016). Some studies find that time-varying hedge ratios can beat the constant competitors given the former's higher effectiveness (Baillie and Myers, 1991; Park and Switzer, 1995). In contrast, other studies disagree where they suggest that utilising time-varying hedging strategies do not improve hedging performance over the constant hedging strategies (Lien and Tse, 2002; Collins, 2000). Park and Jei (2010) further find that time-varying hedge ratios modestly dominate the constant MV hedging ratios if the former hedge ratios are stable and smooth enough. Such superiority, however, is subject to transaction costs incurred by the adjustments of the time-varying hedge ratios.

The main focus of previous studies has been on direct hedging over the underlying spot asset using futures. However, cross-hedging has also been explored by recent studies in equity and commodity markets. Basher and Sadorsky (2016) employed the dynamic conditional correlation (DCC), the asymmetric DCC and the generalised orthogonal GO-GARCH models to estimate time-varying hedge ratios for hedging the MCSI Emerging Markets Index with using the West Texas Intermediate (WTI) crude oil futures, gold futures, US Treasury bond futures and the VIX. They find that hedge ratios from the ADCC model are most effective for the hedging portfolios including oil, VIX, or bonds. The GO-GARCH based hedging strategy is best when using gold to hedge against the emerging stock index. Maghyereh et al. (2017) explore cross-hedging over stock indices in the Gulf Cooperation Council (GCC) countries using Brent crude oil and gold. By utilising a DCC-GARCH model-based hedging strategy, they find that both crude oil and gold can be cheap hedging tools. Belhassine (2020) applied multiple Eurozone sectoral indices to hedge Brent crude oil by utilising a time-varying hedging strategy based on a vector autoregressive (VAR)-BEKK-GARCH model. They focus on the dynamics of the time-varying hedge ratios, identifying that low-cost hedges could be constructed by small hedge ratios. In addition, the compositions of cheap hedging portfolios vary between pre- to post-crisis periods. Junttila et al. (2018) investigate the cross-hedging of the gold and WTI crude oil futures against risks of the S\&P500 Composite Total Return Index and the S\&P500 Energy IG Price Index. Using dynamic hedging strategies based on the DCC- and ADCC-GARCH models, they find that crude oil futures were an attractive instrument during the 2007-2008 financial crisis when compared to gold. However, oil futures were less attractive when the market suffered from backwardation. In addition, using oil futures to hedge energy sectors was identified to be more expensive than expected. Corbet, Goodell, and Günay (2020) identified significant volatility spillovers between the negative WTI price event of April 2020 upon energy sub-sectors, with differential effects observed in the markets for both coal and renewables found to be directly attributed to the negative WTI price which was related to the onset of the COVID-19 pandemic.

As the Chinese stock market plays an increasingly important role in the global financial system, the hedging functionality of the CSI300 index futures has attracted increased academic attention since its launch in 2010. Wei et al. (2011) utilised a multi-fractal volatility (MFV) methodology combined with dynamic copula functions to generate dynamic hedge ratios for the CSI300 index futures. Both direct and cross-hedging over the Chinese stock indices are examined. They find that the copula-MFV model can yield better hedging effectiveness than the copula-GARCH-type models and the former model benefits from lower transaction costs. Hou and Li (2013) assess the hedging performance of the constant hedging strategies, including both constant and wavelet-based models, against B-GARCH-based dynamic hedging strategies for multiple time horizons. They show that direct hedging of the CSI300 index futures favours constant strategies in the long-run whereas dynamic strategies are preferred in the short-run. Yan and Li (2018) used a Markov regime-switching BEKK-GARCH model to construct a hedging strategy for CSI300 index futures where they suggest that the regime-switching BEKK-model provides better performance compared to the BEKK-GARCH and OLS based hedging strategies. Qu et al. (2019) develop dynamic hedge ratios using high-frequency data based on the realised minimum variance (RMV) approach and assess its hedging performance against a set of alternative constant and time-varying hedging ratios. They show that the RMV hedge ratios outperform the other approaches, where the results are found to be robust across several different market structures and volatility regimes.

Substantial changes in social and economic conditions due to COVID-19 have been analysed in detail. Corbet, Larkin, and Lucey (2020) investigate the contagion effects of COVID-19 on gold and cryptocurrency markets. Furthermore, Corbet, Hou, Hu, Lucey, and Oxley (2020) examine the contagion effects relating to similarities in the COVID name on stock markets ${ }^{2}$. Moreover, Conlon et al. (2020) explore evidence of safe-haven and flight-to-safety behaviour in the cryptocurrency markets during the COVID-19 pandemic ${ }^{3}$.

\section{Data}

To analyse hedging effectiveness during crises, we use the daily close prices of the China Securities Index (CSI300), the China Securities Index (CSI300) index futures, and five COVID-19-related stock indices comprised of A-share stocks traded in the Shanghai

\footnotetext{
${ }^{2}$ Such research builds upon work that investigates contagion and spillover effects due to a variety of behavioural effects relating to cryptocurrency dynamics. Important work here includes, (Cioroianu et al., 2020a,b; Meegan et al., 2018; Akhtaruzzaman et al., 2020; Akyildirim, Corbet, Cumming, Lucey, and Sensoy, 2020; Hu et al., 2020; Katsiampa et al., 2019a,b) and (Akyildirim, Corbet, Sensoy, and Yarovaya, 2020). A concise review of cryptocurrency market behaviour is provided by Corbet et al. (2019). Specific research surrounding the COVID-19 pandemic that was used to guide our choice of data and methodological structure include that of Goodell (2020); Goodell and Goutte (2020); Goodell and Huynh (2020), along with COVID-19 research based on fiscal response and recovery dynamics (Seven and Yilmaz, 2021; David et al., 2021); market interactions (Lin and Su, 2021; Goutte et al., 2020; McIver and Kang, 2020; Ashraf, 2020); supply chain disruption (Tang et al., 2021) and corporate social responsibility (Popkova et al., 2021).

${ }^{3}$ (Corbet, Hou, Hu, Larkin, and Oxley, 2020), where accounting for the polarity and subjectivity of social media data based on the development of the COVID-19 outbreak, evidence of safe-haven is found in the major cryptocurrency markets and market returns are significantly affected by negative sentiment associating to COVID-19.
} 
and Shenzhen Stock Exchanges ${ }^{4}$. Data for the CSI300 index and index futures were obtained from Thomson Reuters DataStream, while data for the five COVID-related stock indices are derived from the WIND database. The WIND database is a China-based financial data service provider that serves the domestic financial communities in China as well as foreign qualified investors. Data provided by WIND is widely used in the literature when considering Chinese issues (see, for example, Liu et al., 2019; Allen et al., 2019; Corbet, Hou, Hu, and Oxley, 2020). Following (Corbet, Hou, Hu, Oxley, and Xu, 2020), the COVID concept-based stock indices considered in this paper include the coronavirus index, the facemask index, the influenza index, the coronavirus-detection index, and the disinfectant index. These five indices are representative of the influences of COVID-19 on financial markets in China since their constituent stocks are closely related to activities related ${ }^{5}$ to COVID-19 (Corbet, Hou, Hu, Oxley, and Xu, 2020). Within each index portfolio, the constituent stocks are equally weighted, and the stocks selected from the WIND database are based upon the relevant industrial linkages and characteristics including turnover, market quotation and transaction features.

The sample period is from January 1, 2012, through to September 30, 2020. The starting point of the sample period varies across the other four COVID-related stock indices because they were created later than the coronavirus index by the WIND database. We create six samples consisting of paired price series of the CSI300 index futures and one counterpart including the underlying CSI300 spot and the five COVID-19 related indices. For the continuous index futures price series, we use data from the closest nearby contracts in each calendar month and switch to the next nearby in the contract month based on the trading volume. All the price series are transformed into natural logarithms. The full sample is split into two sub-periods, the first referred to as the pre-COVID period (hereafter labelled as P1), the other is the post-COVID period (hereafter labelled as P2). We follow Corbet, Hou, Hu, Oxley, and Xu (2020) when selecting November 17, 2019, as the start date for the COVID-19 outbreak in China as the South China Morning Post had reported that the first case of COVID-19 was detected in mainland China on November 17, 2019, then identified as a 'mystery pneumonia'. Therefore, P1 runs from January 1, 2012, to November 16, 2019, while P2 from November 17, 2019, to September 30, 2020. For both $\mathrm{P} 1$ and $\mathrm{P} 2$ periods, we use $60 \%$ of the sample for the in-sample estimation on the static hedge ratios and the bivariate GARCH model estimates. Simultaneously, $40 \%$ of the rest of the sample is used for the out-of-sample forecasting on the time-varying hedge ratios, the hedged portfolio returns and the hedging effectiveness ${ }^{6}$. This aligns with Lien and Shrestha (2007), Lai and Sheu (2010), Hou and Li (2013) and Hou and Holmes (2020).

Table 1 presents the descriptive statistics of the return series. Returns are calculated as the first differences of logarithmic prices. The mean performance of all the series is higher in the post-COVID-19 period than in the pre-COVID-19 period. The gap is larger for the COVID-concept based indices. The volatility, as represented by the standard deviation, does not differ substantially between the preand post-COVID-19 periods. The results of the Jarque-Bera test reject the null that the return series follows a normal distribution, such that it is important to account for non-normality in the estimation of the GARCH models. The results of the Ljung-Box test reject no autocorrelation in the squared returns, suggesting that volatility clustering may exist in each return series. This phenomenon will be addressed by the selected GARCH model specification. Fig. 1 presents the daily movements of prices, where it is identified that before the COVID-19 outbreak, there are several sharp price increases and decreases ${ }^{7}$ in the price series of the CSI300 index, the CSI300 index futures, the coronavirus index, and the influenza index across the years 2015 and 2016. Secondly, the daily prices of all the COVIDconcept based stock indices increase during the COVID-19 pandemic. In contrast, sharp decreases in the prices of the CSI300 index and index futures are observed after the COVID-19 outbreak. These observations suggest that even though the COVID-19 outbreak broadly negatively impacts stock markets in China, the firms that are heavily involved in pandemic-related activities obtained larger returns when compared to the pre-COVID-19 period. It is therefore of interest to explore whether the CSI300 stock index futures can provide an efficient hedging function compared to the COVID-19 related index portfolios. Unit root tests suggest that all the price series are integrated of order $1, \mathrm{I}(1)$, while all the return series are integrated at order $0, \mathrm{I}(0)$, during both the pre- and post-COVID-19 periods. We use the Johansen cointegration test to consider the existence of cointegration between the CSI300 index futures and the other indices. Note that the test applies to the pre-defined in-sample estimation window of both the pre-and post-COVID-19 sample periods. We find that in both periods, the CSI300 spot and index futures prices are cointegrated. In the pre-COVID-19 period, the influenza index prices are cointegrated with the CSI300 index futures prices. For the cointegrated series, we employ a vector error correction model (VECM) to model the conditional means of the bivariate SNP distribution. The cointegration test rejects cointegration between the CSI300 index futures and the other index series in the rest of the sample periods. Henceforth a vector autoregressive (VAR) model is used to model the conditional means ${ }^{8}$.

\footnotetext{
${ }^{4}$ Testing of the COVID-related indices enables us to explore the effectiveness of the CSI300 index futures to hedge against risks that the COVID-19 outbreak imposed on the Chinese financial markets.

${ }^{5}$ The coronavirus index consists of 110 publicly listed Chinese firms that conduct business activities related to producing diagnostic reagents, vaccines, antibiotics, antivirals, and masks related to pneumonia. The influenza index comprises 35 A-share companies that produce cold medicines, vaccines, $R \& D$, and manufacturing related to the influenza virus which is also an acute respiratory infection. The facemask index consists of 37 listed firms in China that produce facemasks and related raw materials. The coronavirus detection index includes 24 publicly listed firms in China that focus on research, development, and manufacture of coronavirus testing products. Finally, the disinfectant index is comprised of 21 companies that produce disinfectants, disinfectants, peracetic acid and bleaching powder that can assist in reducing the ineffectiveness of the COVID-19 virus.

${ }^{6}$ One reason for the $60 \%-40 \%$ division of sample is that the choice typically leads to higher reliability and accuracy for the estimation of the hedge ratios and hedging effectiveness.

7 Many of these events relate to the Chinese stock market crash from mid-2015 through to early 2016.

${ }^{8}$ The unit root and Johansen cointegration test results are available upon request.
} 
Table 1

Descriptive statistics of return series.

\begin{tabular}{|c|c|c|c|c|c|c|c|c|}
\hline & CSI300 IF & & CSI300 & & COVID & & Influenza & \\
\hline & $\mathrm{P} 1$ & $\mathrm{P} 2$ & $\mathrm{P} 1$ & $\mathrm{P} 2$ & P1 & P2 & P1 & P2 \\
\hline Mean & $2.44 \mathrm{E}-04$ & $7.06 \mathrm{E}-04$ & $2.45 \mathrm{E}-04$ & 7.38E-04 & 4.59E-04 & 0.003 & $1.58 \mathrm{E}-04$ & 0.002 \\
\hline Median & 0.000 & 5.93E-04 & 0.000 & 7.83E-04 & 0.002 & 0.003 & 0.001 & 0.002 \\
\hline Max & 0.095 & 0.072 & 0.065 & 0.055 & 0.072 & 0.067 & 0.082 & 0.059 \\
\hline Min & -0.105 & -0.098 & -0.092 & -0.082 & -0.102 & -0.067 & -0.096 & -0.067 \\
\hline Std. Dev. & 0.015 & 0.015 & 0.014 & 0.014 & 0.019 & 0.020 & 0.020 & 0.019 \\
\hline Skewness & -0.463 & -1.029 & -0.742 & -1.071 & -0.839 & 0.067 & -0.954 & -0.066 \\
\hline Kurtosis & 12.025 & 12.901 & 9.29 & 9.155 & 6.642 & 4.113 & 8.351 & 4.102 \\
\hline JB & $7.04 \mathrm{E}+03^{* * *}$ & $971.563^{* * *}$ & $3.57 \mathrm{E}+03^{* * *}$ & $403.455^{* * * *}$ & $1.28 \mathrm{E}+03^{* * *}$ & $11.268^{* * *}$ & $1.59 \mathrm{E}+03^{* * *}$ & $11.036^{* * *}$ \\
\hline \multirow[t]{3}{*}{ Q2(12) } & $973.501^{* * *}$ & 5.096 & $726.412^{* * *}$ & 7.279 & $1.26 \mathrm{E}+03^{* * *}$ & $91.991^{* * *}$ & $1.54 \mathrm{E}+03^{* * *}$ & $46.519 * * *$ \\
\hline & Facemask & & COVID Detection & & Disinfectant & & & \\
\hline & $\mathrm{P} 1$ & $\mathrm{P} 2$ & P1 & $\mathrm{P} 2$ & P1 & P2 & & \\
\hline Mean & $-4.03 \mathrm{E}-05$ & 0.003 & $-4.62 \mathrm{E}-04$ & 0.003 & 0.001 & 0.001 & & \\
\hline Median & 0.001 & 4.43E-04 & $-3.54 \mathrm{E}-04$ & 0.005 & 0.001 & 0.002 & & \\
\hline Max & 0.048 & 0.125 & 0.053 & 0.070 & 0.046 & 0.072 & & \\
\hline Min & -0.081 & -0.068 & -0.077 & -0.065 & -0.067 & -0.080 & & \\
\hline Std. Dev. & 0.017 & 0.026 & 0.019 & 0.023 & 0.018 & 0.018 & & \\
\hline Skewness & -0.646 & 0.577 & -0.246 & -0.059 & -0.417 & -0.243 & & \\
\hline Kurtosis & 5.499 & 5.659 & 3.829 & 3.448 & 4.033 & 6.237 & & \\
\hline JB & $61.990^{* * *}$ & $75.265^{\text {*** }}$ & $17.588^{* * *}$ & 1.925 & $13.815^{\text {*** }}$ & $95.977^{* * *}$ & & \\
\hline Q2(12) & $18.922^{*}$ & $92.595^{* * *}$ & 11.916 & $22.625^{\star *}$ & $32.784 * * *$ & $68.096^{* * *}$ & & \\
\hline
\end{tabular}

Note: Return series are calculated as the first differences of logarithmic prices. P1 refers to the sample period running from January 1,2012 to November 16, 2019. P2 refers to the sample period running from November 17, 2019 to September 30, 2020. The starting dates of P1 for the influenza, facemask, coronavirus detection and disinfectant index vary across. CSI300 IF denotes the CSI300 index futures. Max, maximum; Min, minimum; Std. Dev., standard deviation. JB denotes the Jarque-Bera test on normality. Q2(12) denotes the Ljung-Box Q statistic on squared return series up to 12 lags. E stands for the scientific notation.

" significance at the $10 \%$ levels.

*** significance at the $5 \%$ levels.

significance at the $1 \%$ levels.

\section{Methodology}

The hedging and cross-hedging strategies using futures contracts are based upon the concept that uncertainties in the values of a hedged position are reduced by a position in futures contracts. Among a set of hedging strategies, the minimum-variance (MV) hedging strategy is popular among hedgers whereby the goal of minimising the volatility of the hedging portfolio is pursued. Take a short hedge as an example, which is widely analysed in the literature (Chen et al., 2004; Lien and Shrestha, 2007; Park and Jei, 2010; Hou and Li, 2013; Qu et al., 2019), a portfolio consists of a long asset position of $C_{s}$ units and a short futures position of $C_{f}$ units. Denoting the natural logarithms of the hedged asset and futures daily prices as $S_{t}$ and $F_{t}$ at the end of date t, respectively, the return of the hedging portfolio over one day, in line with Chen et al. (2004) and Lien and Shrestha (2007), is shown as:

$$
\Delta V_{H, t}=C_{s} \Delta S_{t}-C_{f} \Delta F_{t}
$$

where $\Delta S_{t}=S_{t}-S_{t-1}$ and $\Delta F_{t}=F_{t}-F_{t-1}$ represent logarithmic daily returns of the hedged asset and futures at date $t$, respectively. According to Lien and Shrestha (2007), the hedge ratio that minimises the variance of $\Delta V_{H, t}$ is calculated as:

$$
h^{*}=\frac{C_{s}}{C_{f}}=\frac{\operatorname{Cov}\left(\Delta S_{t}, \Delta F_{t}\right)}{\operatorname{Var}\left(\Delta F_{t}\right)}
$$

where $\operatorname{Cov}\left(\Delta S_{t}, \Delta F_{t}\right)$ denotes the unconditional covariance and $\operatorname{Var}\left(\Delta F_{t}\right)$ denotes the unconditional variance. $h^{*}$ is referred to as the MV hedge ratio. It should be noted that this paper focuses on short hedging/cross-hedging strategies that reduce the volatility of hedged positions.

\subsection{Constant hedge ratios}

The first constant hedge ratio artificially sets $h^{*}$ in Eq. (2) to unity. Such a ratio is referred to as the naïve hedge ratio. Alternatively, to achieve the minimisation of the hedging portfolio's variance, we follow Eq. (2) by regressing the futures return against the hedged asset return. Henceforth, we have the ordinary least square (OLS) hedge ratio as below

$$
\Delta S_{t}=\alpha+\beta \Delta F_{t}+e_{t}
$$

where the MV hedge ratio $\left(h^{*}\right)$ is an estimate of $\beta$. Although the OLS hedge ratio is simple to estimate and apply, Eq. (3) does not consider a latent cointegration between the hedged asset and futures prices as well as the effects of lagged returns on concurrent ones. 
i) CSI300 Index

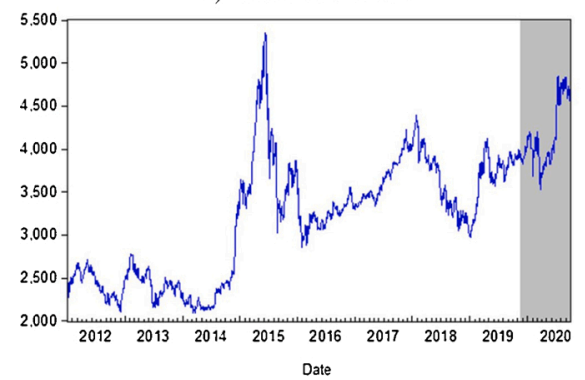

iii) Coronavirus Index

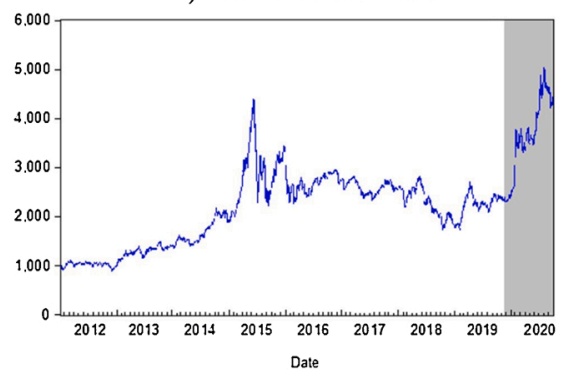

v) Facemask Index

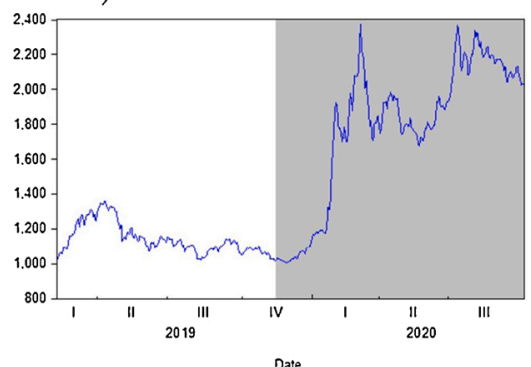

ii) CSI300 Index Futures

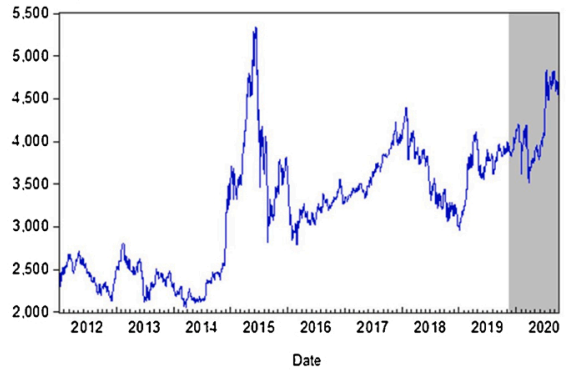

iv) Influenza Index

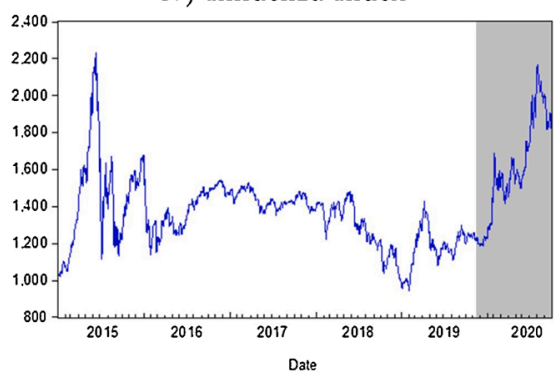

vi) Coronavirus Detection Index

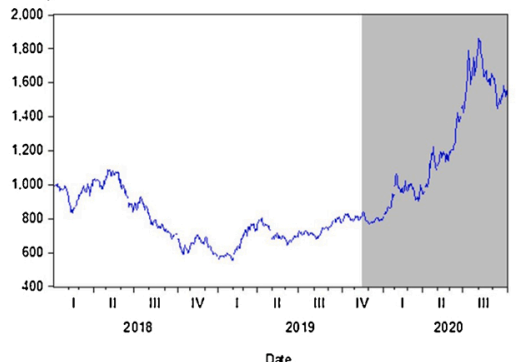

vii) Disinfectant Index

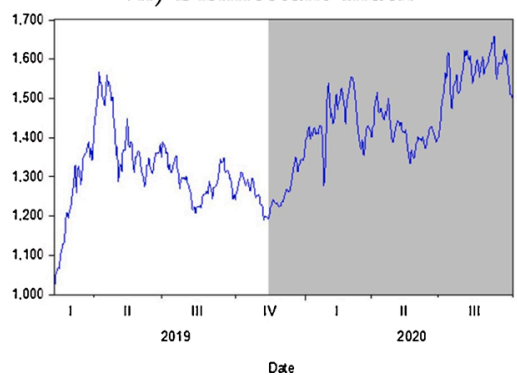

Date

Fig. 1. Movements of daily prices. Note: The shaded area refers to the sample period running from November 17, 2019 to September 30, 2020. I denotes the first quarter; II refers to the second quarter; III refers to the third quarter; and IV refers to the fourth quarter.

In other words, a conditional mean specification on hedged asset return in a bivariate return distribution of hedged asset and futures needs to be considered. Following Lien and Shrestha (2007), the following equation is proposed:

$$
\Delta S_{t}=\beta_{\mathrm{ec}} \Delta F_{t}+a_{0}+a_{1} \mathrm{ec}_{t-1}+\sum_{i=1}^{p} a_{\mathrm{si}} \Delta S_{t-i}+\sum_{j=1}^{q} a_{\mathrm{fj}} \Delta F_{t-j}+\varepsilon_{t}
$$

where ec $\mathrm{e}_{t-1}$ is the lagged error correction term if the cointegration exists between $S_{t}$ and $F_{t}$. Then we have ec $c_{t-1}=S_{t-1}-a-\mathrm{bF}_{t-1}$. In Eq. (4), the MV hedge ratio $\left(h^{*}\right)$ is an estimate of $\beta_{\mathrm{ec}}$. The hedge ratio is referred to as error correction (EC) hedge ratio. Note that if cointegration does not exist between $S_{t}$ and $F_{t}, a_{1}$ is zero and the lagged error correction term is excluded. In such cases the MV hedge 
ratio $\beta_{\mathrm{ec}}$ is referred to here as revised OLS (ROLS) ratio. Compared to Eq. (3), Eq. (4) accounts for the long-run responses of hedged asset prices to lagged deviations of a long-run equilibrium via coefficient $a_{1}$ as well as the temporary effects of lagged asset and futures returns on current asset returns. The lag orders of $\mathrm{p}$ and $\mathrm{q}$ in Eq. (4) are determined by the Akaike Information Criteria (AIC).

We estimate naïve, OLS and EC/ROLS hedge ratios and apply them to the construction of hedging portfolios. It should be noted that all the ratios are assumed to be constant over time, which means that a hedger has to hold the static number of futures contracts until the end of the hedging horizon. Static ratios are unlikely to be efficient when faced with the time-varying dynamics of the second moments of financial returns.

\subsection{Time-varying hedge ratios}

The existing literature acknowledges that the second moments of financial time series can cluster across time. Such phenomenon is explained via an autoregressive conditional heteroscedasticity (ARCH) or a generalised ARCH (GARCH) model (Engle, 1982; Bollerslev, 1986). The GARCH family models suggest that the variance and covariance of financial time series may be conditioned on past information, exhibiting a time-varying nature. In such cases, the unconditional MV hedge ratio in Eq. (2) can be extended to being conditional, as has been explored by a number of prior studies (Bera et al., 1997; Brooks et al., 2002; Baillie and Bollerslev, 2002; Park and Jei, 2010; Hou and Holmes, 2020). The conditional MV hedge ratio is represented by:

$$
h_{t}^{*}=\frac{\operatorname{Cov}\left(\Delta S_{t}, \Delta F_{t} \mid I_{t-1}\right)}{\left.\operatorname{Var}\left(\Delta F_{t} \mid I_{t-1}\right)\right)}
$$

where $I_{t-1}$ is the available information set up to time $t-1$. Time variation of $h_{t}^{*}$ is captured by the conditional covariance of the hedged asset and futures returns as well as the conditional variance of futures returns. To obtain time-varying MV hedge ratios, we adopt three bivariate GARCH models which are widely employed in the literature to specify the conditional variance-covariance matrix of hedged asset and futures returns. The conditional mean of hedged asset and futures returns in a bivariate distribution is specified as a Vector Error Correction Model (VECM) if cointegration exists between the prices of hedged assets and futures. If cointegration does not exist, the VECM reduces to a Vector Autoregressive (VAR) model. The innovations of the VECM/VAR model have the following features:

$$
\varepsilon_{t} \mid I_{t-1} \sim F\left(0, H_{t}\right)
$$

where $\varepsilon_{t}$ is a $2 \times 1$ vector of the innovations and $H_{t}$ is the conditional variance-covariance matrix of $\varepsilon_{t}$. F denotes a bivariate conditional distribution.

We consider the constant conditional correlation (CCC) (Bollerslev, 1990), the dynamic conditional correlation (DCC) (Engle, 2002) and the asymmetric dynamic conditional correlation (ADCC) (Cappiello et al., 2006) GARCH models to specify the conditional variance-covariance matrix $H_{t}$. The multivariate conditional correlation (CC) family GARCH models are adopted because when compared to the alternative, BEKK (Engle and Kroner, 1995) GARCH specification, the CC family specifications can yield better estimates against a variety of time-varying correlation processes and generate more accurate estimates of conditional variances (Tse and Tsui, 2002). Specifically, under the CCC GARCH model, the conditional variance-covariance matrix $H_{t}$ is specified as

$$
H_{t}=D_{t} \mathrm{RD}_{t}
$$

$$
\text { where } D_{t}=\left[\begin{array}{ll}
\sqrt{h_{11, t}} & 0 \\
0 & \sqrt{h_{22, t}}
\end{array}\right] \text { and } R_{t}=\left[\begin{array}{ll}
1 & \rho_{12} \\
\rho_{12} & 1
\end{array}\right]
$$

where $\rho_{12}$ is the constant correlation between the hedged asset and futures returns. $h_{11, t}$ is the conditional variance of hedged asset returns and $h_{22, t}$ is the conditional variance of futures return. Further, the individual conditional variances are specified in an exponential GARCH (EGARCH) model proposed by Nelson (1991). Henceforth we have:

$$
\log \left(h_{\mathrm{ii}, t}\right)=\lambda_{1 i}+\lambda_{2 i}\left|\frac{\varepsilon_{i, t-1}}{\sqrt{h_{\mathrm{ii}, t-1}}}\right|+\lambda_{3 i} \frac{\varepsilon_{i, t-1}}{\sqrt{h_{\mathrm{i}, t-1}}}+\lambda_{4 i} \log \left(h_{\mathrm{ii}, t-1}\right), \quad i=1,2
$$

where $\log \left(h_{\mathrm{ii}, t}\right)$ denotes the natural logarithm. $\lambda_{2 i}$ captures the effects of the lagged shocks and $\lambda_{4 i}$ measures the persistence. $\lambda_{3 i}$ captures asymmetry in the conditional variance where a negative estimate indicates a negative past shock has a larger effect on volatility than an equally positive past shock. The condition for the stationarity of $h_{\mathrm{ii}, t-1}$ is $\lambda_{4 i}$. In contrast to the standard univariate GARCH specification, the EGARCH model ensures the positivity of conditional variance without imposing any restrictions on the estimation of parameters. Furthermore, there are fewer constraints on parameter estimation to guarantee the stationarity of conditional variance. In contrast to the CCC-GARCH model, the DCC-GARCH model is specified as:

$$
H_{t}=D_{t} R_{t} D_{t}
$$

$$
\text { where } D_{t}=\left[\begin{array}{ll}
\sqrt{h_{11, t}} & 0 \\
0 & \sqrt{h_{22, t}}
\end{array}\right] \text { and }
$$




$$
\begin{aligned}
& R_{t}=\left(\operatorname{diag}\left(Q_{t}\right)\right)^{-1 / 2} Q_{t}\left(\operatorname{diag}\left(Q_{t}\right)\right)^{-1 / 2} \text { where } \\
& Q_{t}=\left(1-\theta_{1}-\theta_{2}\right) \bar{Q}+\theta_{1} \varepsilon_{t-1} \varepsilon_{t-1}^{\prime}+\theta_{2} Q_{t-1}
\end{aligned}
$$

where $\varepsilon_{t-1}$ is a $2 x 1$ vector of standardised innovations where $\varepsilon_{t}=\left(\varepsilon_{1 t}, \varepsilon_{2 t}\right)^{\prime}$ and $\varepsilon_{\mathrm{it}}=\frac{\varepsilon_{\mathrm{it}}}{\sqrt{h_{\mathrm{it}}}}, \quad i=1,2$. The conditional variance, $h_{\mathrm{iit}}$ where $(\mathrm{i}=1,2)$, is specified via an EGARCH model, following Eq. (8), $Q_{t}$ is a $2 x 2$ conditional variance-covariance matrix of standardised innovations. $\left.\bar{Q}=E\left[\varepsilon_{t} \varepsilon_{t}^{\prime}\right]\right]$ is the unconditional variance-covariance matrix of standardised innovations. $\theta_{1}$ and $\theta_{2}$ are scalar parameters. To ensure the positive definiteness of $Q_{t}, \theta_{1}>0, \theta_{2}>0$, and $\theta_{1}+\theta_{2}<1$ measures the effect of the lagged shocks on conditional correlation and $\theta_{2}$ examines the persistence of conditional correlation.

Finally, according to Cappiello et al. (2006), the ADCC-GARCH model modifies Eq. (9) by specifying $Q_{t}$ as follows, with all else the same as the DCC model:

$$
Q_{t}=\left(1-\delta_{1}^{2}-\delta_{2}^{2}\right) \bar{R}-\delta_{3}^{2} \bar{S}+\delta_{1}^{2} \varepsilon_{t-1} \varepsilon_{t-1}^{\prime}+\delta_{2}^{2} Q_{t-1}+\delta_{3}^{2} s_{t-1} s_{t-1}^{\prime}
$$

where $\left.\varepsilon_{t}=\left(\varepsilon_{1 t}, \varepsilon_{2 t}\right)^{\prime} \cdot \bar{R}=e\left[\varepsilon_{t} \varepsilon_{t}^{\prime}\right]\right]$ is the unconditional variance-covariance matrix of standardised innovations. $\left.\bar{S}=e\left[\varepsilon_{s} \varepsilon_{s}^{\prime}\right]\right]$ is the unconditional variance-covariance matrix of $S_{t} . S_{t}=\operatorname{Ix} \varepsilon_{T}$ where $i_{t}$ is a $2 x 1$ indicator function that equals to one if $\varepsilon_{t}<0$ and zero otherwise. $\mathrm{x}$ is the element-by-element multiplication operator. $\delta_{1}, \delta_{2}$ and $\delta_{3}$ are scalar parameters. $\delta_{3}^{2}$ controls the asymmetry in conditional correlation in response to the joint past negative shocks. To ensure the positive definiteness of $Q_{t}$, it is required that $\delta_{1}^{2}+$ $\delta_{2}^{2}+\omega \delta_{3}^{2}<1$ where $\omega$ is maximal eigenvalue of $\left[\bar{R}^{-1 / 2} \overline{S R}^{-1 / 2}\right]$.

We utilise a bivariate semi non-parametric (SNP) distribution to obtain estimates of the CCC-, DCC- and ADCC-GARCH models. Compared to some alternatives such as the bivariate conditional normal, Student's $t$ and skew Student's t distributions, the SNP distribution has merit in terms of the estimation of the conditional correlation GARCH-family of models, provided that the conditional distributions of financial time series exhibit asymmetry and fat tails against normality (Bollerslev, 1987; Engle and Gonzalez-Rivera, 1991; Bauwens and Laurent, 2005; Park and Jei, 2010). According to Del Brio et al. (2011), Ñ́guez and Perote (2016) and Del Brio et al. (2017), the SNP distribution straightforwardly adds the marginal skewness and kurtosis terms to the bivariate normal probability density function (PDF), which enables the flexible incorporation of asymmetry and excess kurtosis in a non-normal multivariate distribution. Such features also facilitate the estimation of higher-order moments via a maximum log-likelihood estimation (MLE) procedure via two separate steps. In so doing, the consistency and efficiency of the model estimation can be maintained.

The log-likelihood of a bivariate standardised SNP density that each observation at time t contributes to, excluding unnecessary constant component, is written as:

$$
\begin{aligned}
& l_{t}=-\frac{1}{2} \ln \left|R_{t}\right|-\frac{1}{2} \ln \left|\varepsilon_{t}^{\prime} R_{t}^{-1} \varepsilon_{t}\right|+\ln \left\{\sum_{i=1}^{2} \omega_{i}^{-1} \psi_{i}^{2}\left(x_{\mathrm{it}}\right)\right\} \\
& \text { where } \omega_{i}=1+s_{i}^{2}+k_{i}^{2}, \\
& \psi\left(x_{\mathrm{it}}\right)=1+s_{i}\left(x_{\mathrm{it}}^{3}-3 x_{\mathrm{it}}\right)+k_{i}\left(x_{\mathrm{it}}^{4}-6 x_{\mathrm{it}}^{2}+3\right), \\
& x_{t}=\left(x_{1 t}, x_{2 t}\right)=R_{t}^{-1 / 2} \varepsilon_{t} \\
& \varepsilon_{t}=\left[\varepsilon_{1 t}, \varepsilon_{2 t}\right]^{\prime}
\end{aligned}
$$

where $s_{i}(\mathrm{i}=1,2)$ is the parameter of marginal skewness and $k_{i}(\mathrm{i}=1,2)$ is the parameter of marginal excess kurtosis. $R_{t}$ is the conditional correlation matrix that is specified in the CCC, DCC and ADCC GARCH models. Note that in the CCC model $R_{t}$ changes to $R$ that is the unconditional correlation matrix. The model estimations are obtained via maximising the following equation

$$
L=\sum_{t=1}^{T} l_{t}(\Theta)
$$

where $T$ is the sample size and $\Theta$ is a vector of parameters. There are two steps required for the derivation of the GARCH model estimates. In the first step, the conditional variance equations are estimated via Quasi MLE (QMLE) assuming Gaussian innovations. In the second step, the parameters of the conditional correlations and marginal skewness and excess kurtosis are estimated by maximising the log-likelihood of the bivariate standardised SNP distribution.

\subsection{Measurement of hedging effectiveness}

A hedging strategy is an ex-ante process, which requires a two-step process for implementation (Lai and Sheu, 2010; Lien and Shrestha, 2007; Hou and Li, 2013; Hou and Holmes, 2020). In doing so, we split the full sample into an in-sample estimation window and an out-of-sample forecasting window. Firstly, in-sample estimation is conducted via the in-sample estimation window to derive 
static hedge ratios for a constant hedging strategy. Concerning time-varying hedging strategies, in-sample estimation is used to obtain the GARCH model estimates. Secondly, for constant hedging strategies, we apply static hedge ratios to construct the hedging portfolios via the out-of-sample forecasting window. Aligning with Eq. (1), we obtain the hedging portfolio returns as follows:

$$
\Delta V_{H, t}=\Delta S_{t}-h^{*} \Delta F_{t}
$$

where $h^{*}$ is the estimated static hedge ratio. In terms of the time-varying hedging strategies, we use the GARCH model estimates for recursive forecasting based on conditional variances and covariances, through the out-of-sample forecasting window. The timevarying MV hedge ratios are then derived via the forecasted second moments using Eq. (5). Henceforth returns of the hedging portfolio are denoted as:

$$
\Delta V_{H, t}=\Delta S_{t}-h_{t-1}^{*} \Delta F_{t}
$$

where $h_{t-1}^{*}$ is the forecasted time-varying MV hedge ratio at time t-1. For both constant and time-varying MV hedging strategies, hedging effectiveness is measured by the following equation

$$
\mathrm{VR}=1-\frac{\operatorname{Var}\left(\Delta V_{H, t}\right)}{\operatorname{Var}\left(\Delta S_{t}\right)}
$$

where VR is variance reduction. Var(.) denotes variance. VR measures the percentage reduction in the variance of the hedged asset $\left(\Delta S_{t}\right)$ by the implementation of hedging strategies $\left(\Delta V_{H, t}\right)$ ). Variance reduction is extensively employed to measure hedging effectiveness for the MV hedging strategies in the literature. Furthermore, we consider the hedging effectiveness with transaction costs for the time-varying hedging strategies because the MV hedge ratio is updated based upon the past information; and thus, we have to adjust the units of futures contracts in the hedging portfolio. This incurs transaction fees against the hedging portfolio returns as the adjustments are implemented. Following Hou and Holmes (2020), the returns of the hedging portfolio under transaction fees is shown as:

$$
\Delta V_{H, t}=\Delta S_{t}-h_{t-1}^{*} \Delta F_{t}-\frac{\left|h_{t-1}^{*}-h_{t-2}^{*}\right| F_{t-1 C^{*}}}{\left|S_{t-1}-h_{t-1}^{*} F_{t-1}\right|}
$$

where $c^{*}$ is scaled trading fees relating to one unit of hedged asset. According to the contract specification of the CSI300 index futures, $c^{*}=c / 300$ and 300 is the contract multiplier ${ }^{9}$. As per the trading rules of the China Financial Future Exchange (CFFEX), $c$ is the proportion of the transaction amount of index futures contracts and its maximum value is $0.005 \%$. Here, we adopt the maximal $c$ value of $0.005 \%$ to calculate the hedged portfolio returns via Eq. (16). Variance reduction is then calculated by Eq. (15). We, therefore, consider the hedging effectiveness of the time-varying hedging strategies assuming the maximal transaction cost.

\section{Empirical results}

\subsection{Constant hedge ratios and hedging effectiveness}

Constant hedge ratios and associated hedging effectiveness statistics are presented in Table 2, where we observe the results for P1 and P2, respectively. For each sample period, $60 \%$ of the data is used to estimate OLS and EC/ROLS hedge ratios and $40 \%$ is used to calculate hedging effectiveness. From the results, concerning the hedging strategies against the CSI300 spot index, variance reduction decreases moderately for the naïve strategy post the COVID-19 pandemic occurrence. However, the OLS and EC strategies present significant variance reduction in the same analysed period, suggesting that the outbreak of the COVID-19 had little impact on hedging effectiveness for the constant hedging strategies that use the CSI300 index futures contracts to hedge against the CSI300 spot index. In contrast, the constant cross-hedging strategies for the COVID concept-based stock indices using index futures are found to be significantly affected by the COVID-19 pandemic in terms of hedging performance. For example, between $49 \%$ and $61 \%$ of the volatility of the hedged positions are removed by constant cross-hedging strategies in the pre-COVID-19 period. While between $11 \%$ and $45 \%$ of the volatility of the hedged positions are eliminated by constant strategies post the pandemic occurring. Furthermore, the OLS and ROLS strategies fail to provide hedging effectiveness for the facemask index in the post-COVID-19 period given the negative reduction in variance.

The estimated variance reduction of the optimal constant hedging strategies is found to vary across the hedged stock indices. The optimal strategy for the CSI300 spot index is estimated to be the EC strategy in the period before COVID-19. In the post-COVID-19 period, the best strategies are EC and OLS. Moreover, in the P1 period, the optimal cross-hedging strategies for the COVID conceptbased stock indices are the naïve (for coronavirus index), OLS (for influenza index), naïve and OLS (for the facemask index), naïve and ROLS (for the coronavirus detection index), and OLS and naïve (for the disinfectant index) strategies. Analysing the P2 period, the optimal strategies for the COVID concept-based stock indices transition to the naïve (for coronavirus, facemask, and coronavirus detection indices), ROLS (for influenza index), and OLS (for disinfectant index) strategies. Overall, the cross-hedging strategy for the COVID-related stock indices, the naïve hedging strategy is the most effective before the COVID-19 pandemic, followed by the OLS

${ }^{9}$ Relevant information is accessed via the China Financial Futures Exchange website. 
Table 2

Constant MV hedge ratios and hedging performance.

\begin{tabular}{|c|c|c|c|c|c|c|}
\hline & CSI300 & COVID & Influenza & Facemask & COVID detection & Disinfectant \\
\hline \multicolumn{7}{|l|}{ Naïve } \\
\hline \multicolumn{7}{|l|}{ P1 } \\
\hline Hedge ratio & 1.000 & 1.000 & 1.000 & 1.000 & 1.000 & 1.000 \\
\hline VR & 0.919 & 0.488 & 0.605 & 0.538 & 0.597 & 0.527 \\
\hline \multicolumn{7}{|l|}{$P 2$} \\
\hline Hedge ratio & 1.000 & 1.000 & 1.000 & 1.000 & 1.000 & 1.000 \\
\hline VR & 0.915 & 0.349 & 0.328 & 0.293 & 0.203 & 0.397 \\
\hline \multicolumn{7}{|l|}{ OLS } \\
\hline \multicolumn{7}{|l|}{$P 1$} \\
\hline Hedge ratio & 0.871 & 0.825 & 0.930 & 0.983 & 0.976 & 1.007 \\
\hline VR & 0.921 & 0.485 & 0.614 & 0.538 & 0.596 & 0.527 \\
\hline \multicolumn{7}{|l|}{$P 2$} \\
\hline Hedge ratio & 0.916 & 0.158 & 0.206 & -0.138 & 0.221 & 0.817 \\
\hline VR & 0.925 & 0.137 & 0.170 & -0.141 & 0.114 & 0.453 \\
\hline \multicolumn{7}{|l|}{ EC/ROLS } \\
\hline \multicolumn{7}{|l|}{$P 1$} \\
\hline Hedge ratio & 0.903 & 0.830 & 0.973 & 0.949 & 0.993 & 0.974 \\
\hline VR & 0.924 & 0.486 & 0.609 & 0.535 & 0.597 & 0.526 \\
\hline \multicolumn{7}{|l|}{$P 2$} \\
\hline Hedge ratio & 0.923 & 0.260 & 0.941 & -0.165 & 0.232 & 0.838 \\
\hline VR & 0.925 & 0.209 & 0.344 & -0.171 & 0.118 & 0.449 \\
\hline
\end{tabular}

Note: This table reports constant MV hedge ratios and their resulted hedging effectiveness during both the pre- and post-COVID-19 periods. The first row shows stock index portfolios that are hedged against using the CSI300 index futures. P1 refers to the sample period running from January 1 , 2012 to November 16, 2019. P2 refers to the sample period running from November 17, 2019 to September 30, 2020. The starting dates of P1 for the influenza, facemask, coronavirus detection and disinfectant index vary across. For each sample period, $60 \%$ of the sample is used to estimate hedge ratios and the rest $40 \%$ of the sample is employed to forecast hedging effectiveness. Naïve, the naïve hedging strategy; OLS, the OLS hedging strategy; EC/ROLS, the Error Correction/Revised OLS hedging strategy. VR denotes variance reduction.

strategy. However, in the post-COVID-19 period, the naïve strategy performs best compared to the others considered. The results suggest that the COVID-19 pandemic affects the choice of the optimal constant hedging strategy, especially when it is required to hedge against the COVID-related stock portfolios. The naïve hedging strategy is estimated to be the most optimal to select when demand for cross-hedging of COVID-19 stock portfolios arises.

\subsection{Time-varying hedge ratios and hedging effectiveness}

Table 3 presents the estimation results for the bivariate CCC-, DCC-, and ADCC-GARCH models. The volatility of the CSI300 spot index is significantly affected by the recent shocks. Persistence in the estimated volatility is also apparent. Result holds for the P1 period. While in the P2 period, a similar result is maintained, and also recent negative shocks present differing impacts on volatility compared to recent positive shocks, as do the estimated volatilities of the stock index futures. Concerning the COVID-19-related stock indices, volatilities are found to be conditional on past information. Both recent shocks and lagged volatility significantly impact current volatility. Negative shocks behave differently from recent positive shocks in terms of explanatory power, particularly in the P2 period.

Moreover, constant conditional correlations between stock indices and index futures are all significant across samples. The constant correlations are positive with a large magnitude. The DCC-GARCH result suggests that the pairwise correlations can be significantly explained by recent COVID-19-related shocks, where some also exhibit persistence. Recent joint negative shocks in both markets play a critical role in driving conditional correlations. Finally, we find that the marginal excess kurtosis parameter is significant across samples, suggesting that it is important for explaining the non-normality of the bivariate return distribution. The Ljung-Box test result indicates that there are no autocorrelations in either the standardised residuals or their squares. The bivariate GARCH models, therefore, seem well specified, with the results holding for both P1 and P2.

The results of the forecasted time-varying MV hedge ratios from the bivariate GARCH models are presented in Table 4, in terms of their means, medians, and standard deviations. For the CCC-GARCH model, the mean hedge ratio for the coronavirus index decreases from P1 to P2, whereas the mean hedge ratios for the CSI300 spot index and the other four COVID-19 concept-based stock indices increase from P1 to P2. The situation changes for the DCC-GARCH model where the mean hedge ratios for all the stock index portfolios decrease from P1 to P2. The result from the ADCC-GARCH model appears to be less clear. The mean hedge ratios for the CSI300 spot index, the coronavirus index, the facemask index, and the disinfectant index decrease from P1 to P2. In contrast, the means for the other two COVID-19 related indices increase from P1 to P2. Furthermore, the standard deviations of the time-varying MV hedge ratios increase from P1 to P2, which is evidenced for all the GARCH models and all the stock indices. One exception is the standard deviation of the time-varying hedge ratio for the CSI300 spot index forecasted from the CCC model, which decreases from P1 to P2. The results presented in Table 4 suggest that taking account of the dynamics of the conditional correlation between the hedged asset and the index futures affects the behaviour of the hedge ratios in terms of their magnitudes. The COVID-19 pandemic appears to affect such behaviour. Moreover, accounting for the dynamics of the conditional correlation influences the volatility of the time-varying hedge 
Table 3

The bivariate GARCH models.

\begin{tabular}{|c|c|c|c|c|c|c|c|c|c|c|c|c|}
\hline & \multicolumn{2}{|c|}{ CSI300-CSI300F } & \multicolumn{2}{|c|}{ COVID-CSI300F } & \multicolumn{2}{|c|}{ Influenza-CSI300F } & \multicolumn{2}{|c|}{ Facemask-CSI300F } & \multicolumn{2}{|c|}{ C19Detect.-CSI300F } & \multicolumn{2}{|c|}{ Disinfectant-CSI300F } \\
\hline & P1 & P2 & P1 & P2 & P1 & P2 & P1 & P2 & P1 & P2 & P1 & P2 \\
\hline \multicolumn{13}{|c|}{ Panel A: Individual EGARCH estimates } \\
\hline$\lambda_{11}$ & $-0.190^{* * *}$ & $-1.301^{* * *}$ & $-0.184^{* * * *}$ & $-1.400^{*}$ & $-0.148^{* * *}$ & $-6.605 *$ & $-14.644^{* * *}$ & $-7.013^{* * *}$ & $-0.708^{* *}$ & $-0.944^{* * *}$ & -1.77 & $-2.948^{* *}$ \\
\hline$\lambda_{21}$ & $0.119^{* * *}$ & $-0.188^{* * *}$ & $0.131^{* * *}$ & 0.194 & $0.121^{* * *}$ & $0.347^{*}$ & -0.092 & $0.760^{* * *}$ & $-0.129^{* *}$ & 0.026 & 0.162 & $0.816^{* * *}$ \\
\hline$\lambda_{31}$ & 4.12E-04 & 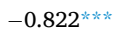 & -0.008 & $0.281^{* *}$ & -0.004 & $0.307^{* *}$ & $0.235^{*}$ & $0.316^{\text {*炏 }}$ & $-0.095^{\star *}$ & $0.431^{* * *}$ & -0.032 & -0.1 \\
\hline$\lambda_{41}$ & $0.988^{* * * *}$ & $0.835^{\text {决火 }}$ & $0.989^{* * *}$ & $0.844^{* * *}$ & $0.994^{* * *}$ & 0.233 & $-0.839^{* * *}$ & 0.123 & $0.898^{* * *}$ & $0.881^{\text {*决决 }}$ & $0.789^{* * * *}$ & $0.723^{* * *}$ \\
\hline$\lambda_{12}$ & $-0.269^{* * * *}$ & $-1.742^{\text {*水火 }}$ & $-0.295^{* * *}$ & $-3.044^{* * *}$ & $-0.141^{* * *}$ & $-2.661^{\text {**** }}$ & $-4.119^{* *}$ & $-3.719^{* * *}$ & $-1.494 *$ & $-4.073^{* * * *}$ & $-15.473^{\text {*** }}$ & $-2.854 * * *$ \\
\hline$\lambda_{22}$ & $0.143^{* * *}$ & $-0.291^{* * *}$ & $0.174^{* * *}$ & 0.103 & $0.122^{* * *}$ & 0.121 & $-0.577^{* * *}$ & 0.071 & 0.165 & 0.157 & $0.334 * * *$ & 0.147 \\
\hline$\lambda_{32}$ & -0.01 & 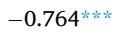 & $-0.027^{* * *}$ & $-0.714^{* * *}$ & -0.006 & $-0.704^{* \cdots * k}$ & -0.189 & $-0.757^{* * *}$ & $-0.166^{\text {*k* }}$ & 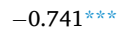 & 0.105 & $-0.698^{* * *}$ \\
\hline$\lambda_{42}$ & $0.981^{* * * *}$ & $0.778^{* * * *}$ & $0.980^{* * *}$ & $0.665^{* * *}$ & $0.995^{* * *}$ & $0.709^{* * *}$ & $0.463^{\text {** }}$ & $0.589 * * *$ & $0.840^{* * * *}$ & $0.555^{* * *}$ & $-0.827^{* * * *}$ & $0.689^{* * * *}$ \\
\hline \multirow{2}{*}{\multicolumn{13}{|c|}{$\begin{array}{l}\text { Panel B: Conditional correlations } \\
\text { CCC }\end{array}$}} \\
\hline & & & & & & & & & & & & \\
\hline$\rho_{12}$ & $0.979^{* * *}$ & $0.981^{* * *}$ & $0.807^{* * *}$ & $0.570^{* \star *}$ & $0.857^{* * *}$ & $0.713^{* * *}$ & $0.774^{* * *}$ & $0.737^{* \ldots *}$ & $0.874^{* \ldots *}$ & $0.789^{* * *}$ & $0.733^{* * *}$ & $0.742^{* * *}$ \\
\hline \multicolumn{13}{|c|}{ DCC } \\
\hline$\theta_{1}$ & $0.133^{* * *}$ & $0.618^{*}$ & 0.032 & $0.561^{* * *}$ & $0.282^{* * *}$ & $0.747^{\cdots * *}$ & $0.501^{* * *}$ & $0.385^{\ldots * * k}$ & $0.291^{* * *}$ & $0.836^{* * *}$ & $0.638^{* * * *}$ & $0.295^{* * *}$ \\
\hline$\theta_{2}$ & $0.410^{* * * *}$ & -0.02 & $0.379 *$ & -0.104 & 0.035 & 0.002 & -0.047 & -0.07 & $0.306^{* * *}$ & -0.002 & $0.258^{*}$ & -0.186 \\
\hline \multicolumn{13}{|c|}{ ADCC } \\
\hline$\delta_{1}$ & $5.22 \mathrm{E}-10$ & 5.79E-09 & $1.64 \mathrm{E}-09$ & $0.324 * * *$ & $0.332^{* * *}$ & $0.150^{* *}$ & $-3.54 \mathrm{E}-12$ & $0.524 * * *$ & 2.67E-11 & $-9.85 \mathrm{E}-12$ & $0.388^{*}$ & $0.454 * * *$ \\
\hline$\delta_{2}$ & $0.893^{* * *}$ & $0.428^{* * *}$ & $-0.994^{* * *}$ & $0.966^{* * *}$ & $0.949^{* * *}$ & $0.956^{* k^{* k}}$ & $0.752^{* * * *}$ & $1.52 \mathrm{E}-10$ & $0.999 * * *$ & $0.981^{* * *}$ & $0.772^{* * * *}$ & $0.712^{* * *}$ \\
\hline$\delta_{3}$ & $0.495^{* \cdots *}$ & $0.659^{* \cdots * k}$ & $-0.306^{* * *}$ & $1.01 \mathrm{E}-09$ & $0.357^{\text {k*k }}$ & $0.432^{* \cdots *}$ & $0.848^{* \cdots k}$ & $-0.447^{*}$ & $0.150^{* * *}$ & $0.370^{* \cdots * k}$ & 0.175 & $0.629^{* * *}$ \\
\hline \multirow{2}{*}{\multicolumn{13}{|c|}{$\begin{array}{l}\text { Panel C: Marginal skewness and kurtosis parameters } \\
\text { CCC }\end{array}$}} \\
\hline & & & & & & & & & & & & \\
\hline$s_{1}$ & 0.05 & 0.17 & 0.176 & 198.848 & $0.911^{* *}$ & -0.837 & 2.127 & 1.486 & -3.606 & -4.073 & -1.545 & 0.182 \\
\hline$k_{1}$ & $12.530^{* * *}$ & $5.758^{* * *}$ & $11.564^{* * *}$ & -63.831 & $9.971^{* * *}$ & $7.920^{* * *}$ & 20.954 & 33.228 & 30.057 & 48.341 & 12.48 & $9.255^{* *}$ \\
\hline$s_{2}$ & -0.026 & -0.565 & 0.204 & -0.538 & 0.455 & $-0.865^{*}$ & 0.038 & 0.012 & 0.055 & 0.221 & -0.124 & $-1.739^{* *}$ \\
\hline$k_{2}$ & $13.490^{* * *}$ & $6.880^{* * *}$ & $6.982^{* k^{*} *}$ & $4.503^{* * *}$ & $9.341^{* * *}$ & $6.166^{* * * k}$ & $5.909^{* * *}$ & $2.676^{* * *}$ & $10.773^{* * *}$ & 17.961 & $5.007^{\text {决决 }}$ & $7.972^{* * *}$ \\
\hline
\end{tabular}


Table 3 (continued)

\begin{tabular}{|c|c|c|c|c|c|c|c|c|c|c|c|c|}
\hline & \multicolumn{2}{|c|}{ CSI300-CSI300F } & \multicolumn{2}{|c|}{ COVID-CSI300F } & \multicolumn{2}{|c|}{ Influenza-CSI300F } & \multicolumn{2}{|c|}{ Facemask-CSI300F } & \multicolumn{2}{|c|}{ C19Detect.-CSI300F } & \multicolumn{2}{|c|}{ Disinfectant-CSI300F } \\
\hline & P1 & P2 & P1 & P2 & P1 & P2 & P1 & P2 & P1 & P2 & P1 & P2 \\
\hline \multicolumn{13}{|l|}{ DCC } \\
\hline$s_{1}$ & -0.255 & -0.058 & -0.37 & 0.513 & 0.39 & 0.258 & 0.086 & 0.495 & -0.841 & -22.223 & -0.967 * & -0.022 \\
\hline$k_{1}$ & $6.397^{* * *}$ & $4.158^{* * *}$ & $10.643^{* * *}$ & 11.505 & $6.988^{* * *}$ & $8.908^{* * *}$ & 8.307 & 7.525 & $10.804^{* * *}$ & 134.65 & $7.310^{* * *}$ & 8.203 \\
\hline$s_{2}$ & 0.043 & $-0.622^{* *}$ & 0.238 & $-0.717^{* *}$ & 0.08 & $-0.857^{* *}$ & -0.057 & -0.027 & 0.577 & $1.761^{*}$ & -0.498 & -0.533 \\
\hline$k_{2}$ & $6.223^{\text {*k* }}$ & $4.836^{* * * *}$ & $5.314^{* * *}$ & $3.476^{* * *}$ & $6.048^{* * * k}$ & $5.298^{* k *}$ & 5.444 & 2.942 & $8.092^{* * * k}$ & $9.171^{* * *}$ & $6.258^{* * *}$ & 7.23 \\
\hline \multicolumn{13}{|l|}{ ADCC } \\
\hline$s_{1}$ & -0.059 & -0.609 & 0.056 & 2.332 & 0.653 & -0.27 & 0.151 & 0.617 & -1.149 & -1.958 & -1.267 & -0.466 \\
\hline$k_{1}$ & $6.973^{* * *}$ & $6.476^{*}$ & $9.828^{* * *}$ & 16.606 & $6.987^{*}$ & $12.683^{* *}$ & 10.194 & 6.974 & 17.022 & 25.915 & 7.195 & 8.106 \\
\hline$s_{2}$ & $0.439 *$ & 0.8 & $0.388^{*}$ & -0.428 & 0.026 & -0.74 & 0.095 & -0.003 & 0.379 & -0.535 & -0.475 & -0.507 \\
\hline$k_{2}$ & $6.494^{* * *}$ & 7.511 & $6.834^{* * *}$ & $4.485^{* * *}$ & $6.824^{*}$ & $6.960^{* * * k}$ & $5.553^{*}$ & $2.946^{* * *}$ & $7.519^{* *}$ & $5.098^{* *}$ & $5.367^{*}$ & $6.235^{*}$ \\
\hline \multicolumn{13}{|c|}{ Panel D: Residual diagnosis } \\
\hline $\mathrm{Q}(12)(\mathrm{i}=1)$ & 4.319 & 10.333 & 3.96 & 7.923 & 5.142 & 8.016 & 12.629 & 10.104 & 4.29 & 12.24 & 9.7487 & 10.119 \\
\hline $\mathrm{Q} 2(12)(\mathrm{i}=1)$ & 18.657 & 7.599 & 18.882 & 3.946 & 18.244 & 11.933 & 7.755 & 3.474 & 7.741 & 8.44 & 5.3038 & 7.49 \\
\hline $\mathrm{Q}(12)(\mathrm{i}=2)$ & 12.664 & 8.812 & 10.562 & 10.192 & 11.851 & 10.323 & 11.537 & 8.471 & 12.733 & 9.76 & 9.4798 & 11.959 \\
\hline $\mathrm{Q} 2(12)(\mathrm{i}=2)$ & 25.052 & 7.233 & 18.83 & 5.376 & 9.26 & 4.566 & 4.518 & 8.485 & 16.372 & 6.59 & 5.4393 & 4.542 \\
\hline AIC (CCC) & -5.845 & -6.587 & -4.093 & -2.74 & -4.322 & -3.66 & -4.279 & -4.536 & -4.215 & -3.724 & -4.027 & -3.908 \\
\hline AIC (DCC) & -5.586 & -5.041 & -3.906 & -3.206 & -3.982 & -3.395 & -4.078 & -4.679 & -4.021 & -3.417 & -3.993 & -3.711 \\
\hline AIC (ADCC) & -5.603 & -6.223 & -4.051 & -3.432 & -4.109 & -3.773 & -4.123 & -4.656 & -4.095 & -3.421 & -3.926 & -3.841 \\
\hline
\end{tabular}

Note: This table reports the estimation result of the bivariate CCC, DCC and ADCC GARCH models. P1 refers to the sample period running from January 1, 2012 to November 16, 2019. P2 refers to the

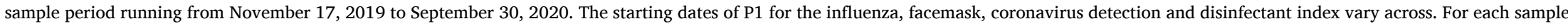

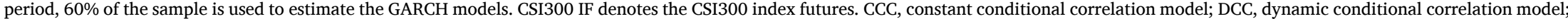
ADCC, asymmetric dynamic conditional correlation model. $\mathrm{Q}(12)(\mathrm{i}=1)$ and $\mathrm{Q}^{2}(12)(\mathrm{i}=1)$ are the Ljung-Box $\mathrm{Q}$ test statistic up to 12 lag orders for standardized residuals and its squares of stock index

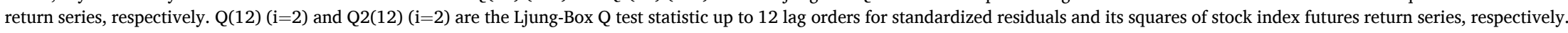
AIC, Akaike Information Criterion. E denotes the scientific notation. Figures in the parentheses are $\mathrm{p}$ value for associated t test statistic.

"significance at the $10 \%$ levels.

significance at the $5 \%$ levels.

significance at the $1 \%$ levels. 
Table 4

Time-varying MV hedge ratios.

\begin{tabular}{|c|c|c|c|c|c|c|}
\hline & \multicolumn{2}{|c|}{ CSI300 - CSI300 IF } & \multicolumn{2}{|c|}{ COVID - CSI300 IF } & \multicolumn{2}{|c|}{ Influenza - CSI300 IF } \\
\hline & P1 & P2 & P1 & P2 & P1 & P2 \\
\hline \multicolumn{7}{|l|}{ CCC } \\
\hline Mean & 0.946 & 1.033 & 1.035 & 0.938 & 0.945 & 0.988 \\
\hline Median & 0.978 & 1.034 & 1.035 & 0.882 & 0.946 & 0.938 \\
\hline \multicolumn{6}{|l|}{ DCC } & 0.229 \\
\hline Mean & 0.921 & 0.610 & 0.809 & 0.659 & 0.878 & 0.585 \\
\hline Median & 0.949 & 0.741 & 0.812 & 0.685 & 0.886 & 0.686 \\
\hline Std. Dev. & 0.058 & 0.400 & 0.120 & 0.652 & 0.102 & 0.658 \\
\hline \multicolumn{7}{|l|}{ ADCC } \\
\hline Mean & 0.932 & 0.723 & 0.901 & 0.883 & 0.820 & 0.927 \\
\hline Median & 0.961 & 0.734 & 0.925 & 1.136 & 0.867 & 0.975 \\
\hline \multirow[t]{3}{*}{ Std. Dev. } & 0.065 & 0.090 & 0.244 & 0.593 & 0.165 & 0.333 \\
\hline & \multicolumn{2}{|c|}{ Facemask - CSI300 IF } & \multicolumn{2}{|c|}{ COVID Det. - CSI300 IF } & \multicolumn{2}{|c|}{ Disinfectant - CSI300 IF } \\
\hline & P1 & P2 & P1 & P2 & P1 & P2 \\
\hline \multicolumn{7}{|l|}{ CCC } \\
\hline Mean & 0.811 & 1.697 & 1.168 & 1.470 & 0.933 & 1.005 \\
\hline Median & 0.797 & 1.633 & 1.174 & 1.381 & 0.921 & 0.960 \\
\hline Std. Dev. & 0.140 & 0.350 & 0.015 & 0.349 & 0.150 & 0.192 \\
\hline \multicolumn{7}{|l|}{ DCC } \\
\hline Mean & 0.734 & 0.621 & 0.961 & 0.689 & 0.890 & 0.771 \\
\hline Median & 0.707 & 0.677 & 0.971 & 0.887 & 0.960 & 0.798 \\
\hline Std. Dev. & 0.186 & 0.645 & 0.142 & 1.076 & 0.305 & 0.369 \\
\hline \multicolumn{7}{|l|}{ ADCC } \\
\hline Mean & 0.844 & 0.667 & 1.127 & 1.146 & 0.895 & 0.825 \\
\hline Median & 0.827 & 0.632 & 1.143 & 1.315 & 0.884 & 0.844 \\
\hline Std. Dev. & 0.172 & 0.496 & 0.051 & 0.422 & 0.153 & 0.338 \\
\hline
\end{tabular}

Note: This table reports the mean, median and standard deviation of the time-varying MV hedging ratios. The hedge ratios are forecasted based on the CCC, DCC and ADCC GARCH model estimates. P1 refers to the sample period running from January 1, 2012 to November 16, 2019. P2 refers to the sample period running from November 17, 2019 to September 30, 2020. The starting dates of P1 for the influenza, facemask, coronavirus detection and disinfectant index vary across. For each sample period, $60 \%$ of the sample is used to estimate the GARCH models and the rest $40 \%$ of the sample is used to forecast the time-varying hedging ratios. CCC, constant conditional correlation model; DCC, dynamic conditional correlation model; ADCC, asymmetric dynamic conditional correlation model. CSI300 IF is the CSI300 index futures. Std. Dev. denotes standard deviation.

ratio. The COVID-19 pandemic increases the extent of the ratio's variation over time. This result corresponds to heightened market turbulence once COVID-19 contagion effects begin in China.

Next, we focus on the hedging effectiveness of the time-varying hedge ratios based on the GARCH models. Table 5 presents the results for both the P1 and P2 periods, initially without the adjustment for transaction costs from adjusting hedge ratios daily. First, hedge ratios based on the CCC-, DCC- and ADCC-GARCH models provide evidence of variance reduction in the P1 period, with approximately $92 \%$ to $93 \%$ of the variance in the CSI300 spot index removed. However, hedging effectiveness decreases substantially from P1 to P2 as to hedge ratios from the DCC and ADCC models are approximately $68 \%$ to $89 \%$ of the variance in the hedged position is eliminated in the post-COVID-19 period. Staying with the P2 period, the hedge ratio from the CCC model also leads to variance reduction compared to that in P1. However, approximately $91 \%$ of the variance in the hedged position can still be removed. Concerning hedging effectiveness of the time-varying cross-hedging strategy over the COVID concept-based stock indices, it is apparent from Table 5 that variance reduction from P1 to P2 falls substantially, which is evidenced for all of the analysed indices. In the P2 period, we find that the CSI300 index futures fail to provide an effective cross-hedging function to the facemask and coronavirus detection indices, due to the negative variance reduction given by the CCC- and DCC-hedge ratios for the facemask index and the DCC hedge ratio for the coronavirus detection index. In the P1 period, between $47 \%$ and $61 \%$ of the variance in the hedged COVID related stock index is removed by the GARCH based hedge ratios. In contrast, only approximately $5 \%$ to $41 \%$ of the variance in the hedged position is removed in the P2 period. The outbreak of the COVID-19 pandemic significantly reduces the hedging performance of the CSI300 index futures when the GARCH based cross-hedging strategies apply to the COVID concept-based stock index portfolios.

We also explore the best GARCH hedging strategy for each stock index in Table 5. In the P1 period, the DCC hedge ratio presents the highest variance reduction, while the best strategy changes to the CCC model when moving to the P2 period. Considering crosshedging over the coronavirus index, the best strategy in P1 is the ADCC model whereas the best one in P2 is the CCC model. Turning to the influenza index, the best strategy in P1 is the CCC model, which changes to the ADCC model in P2. For the cross-hedging of the facemask and coronavirus detection indices, the best strategy remains the ADCC model in both P1 and P2. When we look at the cross-hedging over the disinfectant index, the CCC model remains the best strategy in both P1 and P2. Hence, we find that the best GARCH hedging strategy varies across stock indices to be hedged against. In the pre-COVID-19 period, the ADCC hedging strategy performs best with the CCC next. In the post-COVID-19 period, the CCC and ADCC hedging strategies are equally optimal for the three stock indices. Overall, the ADCC hedging strategy seems to be the optimal time-varying strategy to hedge against the risk of the CSI300 index and the COVID concept-based stock indices using the CSI300 index futures.

Table 6 presents the results of the analysis based on the hedging effectiveness of the time-varying GARCH hedging strategies in P1 
Table 5

Hedging performance of time-varying MV hedge ratios.

\begin{tabular}{|c|c|c|c|c|c|c|}
\hline & \multicolumn{2}{|c|}{ CSI300 - CSI300 IF } & \multicolumn{2}{|c|}{ COVID - CSI300 IF } & \multicolumn{2}{|c|}{ Influenza - CSI300 IF } \\
\hline & P1 & P2 & P1 & P2 & P1 & P2 \\
\hline \multicolumn{7}{|l|}{ CCC } \\
\hline VR & 0.923 & 0.906 & 0.468 & 0.362 & 0.613 & 0.337 \\
\hline \multicolumn{7}{|l|}{ DCC } \\
\hline VR & 0.925 & 0.682 & 0.470 & 0.227 & 0.606 & 0.172 \\
\hline \multicolumn{7}{|l|}{ ADCC } \\
\hline \multirow[t]{3}{*}{ VR } & 0.924 & 0.886 & 0.481 & 0.242 & 0.606 & 0.406 \\
\hline & \multicolumn{2}{|c|}{ Facemask - CSI300 IF } & \multicolumn{2}{|c|}{ COVID Det. - CSI300 IF } & \multicolumn{2}{|c|}{ Disinfectant - CSI300 IF } \\
\hline & P1 & P2 & P1 & P2 & P1 & P2 \\
\hline \multicolumn{7}{|l|}{ CCC } \\
\hline VR & 0.509 & -0.197 & 0.590 & 0.046 & 0.500 & 0.404 \\
\hline \multicolumn{7}{|l|}{ DCC } \\
\hline VR & 0.488 & -0.049 & 0.567 & -0.361 & 0.441 & 0.374 \\
\hline \multicolumn{7}{|l|}{ ADCC } \\
\hline VR & 0.539 & 0.233 & 0.597 & 0.256 & 0.488 & 0.385 \\
\hline
\end{tabular}

Note: This table reports hedging effectiveness of time-varying MV hedge ratios based on the CCC, DCC and ADCC GARCH models. P1 refers to the sample period running from January 1, 2012 to November 16, 2019. P2 refers to the sample period running from November 17, 2019 to September 30, 2020. The starting dates of P1 for the influenza, facemask, coronavirus detection and disinfectant index vary across. For each sample period, $60 \%$ of the sample is used to estimate the GARCH models and the rest $40 \%$ of the sample is used to forecast the time-varying hedging ratios and their hedging effectiveness. CCC, constant conditional correlation model; DCC, dynamic conditional correlation model; ADCC, asymmetric dynamic conditional correlation model. VR, variance reduction. CSI300 IF is the CSI300 index futures.

and P2 when the maximal transaction cost of adjusting hedge ratios daily is considered. Compared to Table 5, most results in Table 6 suggest that with transaction costs, variance reduction falls, however, this reduction is small. Furthermore, from Table 6 , the outbreak of the COVID-19 pandemic decreases the hedging effectiveness of the GARCH hedging strategies. The best GARCH hedging strategy in P1 is the ADCC model and the second best is the CCC model. In P2, both the CCC and ADCC models offer the best performance respectively for three stock indices. The ADCC hedging strategy remains the most appropriate model around the time windows of the COVID-19 pandemic. These results are similar to Table 5. When we include transaction cost their influence on the performance of the GARCH hedging strategies is limited.

\subsection{A comparison of hedging performance}

Finally, we compare the best constant strategies from Table 2 with the best time-varying GARCH strategies in Table 6 in terms of hedging effectiveness. During P1, when considering hedging against the CSI300 spot index, the DCC-GARCH strategy outperforms the constant EC strategy as can be evidenced through slightly improved variance reduction. The result aligns with Hou and Li (2013) and Qu et al. (2019) where the time-varying MV hedge ratios outperform the constant counterparts before the COVID-19 pandemic occurs.

Table 6

Hedging performance of time-varying MV hedge ratios and transaction cost.

\begin{tabular}{|c|c|c|c|c|c|c|}
\hline & \multicolumn{2}{|c|}{ CSI300 - CSI300 IF } & \multicolumn{2}{|c|}{ COVID - CSI300 IF } & \multicolumn{2}{|c|}{ Influenza - CSI300 IF } \\
\hline & P1 & P2 & P1 & P2 & P1 & P2 \\
\hline \multicolumn{7}{|l|}{ CCC } \\
\hline VR & 0.923 & 0.905 & 0.468 & 0.356 & 0.616 & 0.330 \\
\hline \multicolumn{7}{|l|}{ DCC } \\
\hline VR & 0.925 & 0.678 & 0.470 & 0.218 & 0.609 & 0.162 \\
\hline \multicolumn{7}{|c|}{ ADCC } \\
\hline \multirow[t]{3}{*}{ VR } & 0.924 & 0.884 & 0.480 & 0.233 & 0.609 & 0.399 \\
\hline & \multicolumn{2}{|c|}{ Facemask - CSI300 IF } & \multicolumn{2}{|c|}{ COVID Det. - CSI300 IF } & \multicolumn{2}{|c|}{ Disinfectant - CSI300 IF } \\
\hline & P1 & P2 & P1 & P2 & P1 & P2 \\
\hline \multicolumn{7}{|l|}{ CCC } \\
\hline VR & 0.505 & -0.205 & 0.589 & 0.035 & 0.493 & 0.399 \\
\hline \multicolumn{7}{|l|}{ DCC } \\
\hline VR & 0.483 & -0.052 & 0.562 & -0.378 & 0.434 & 0.368 \\
\hline \multicolumn{7}{|c|}{ ADCC } \\
\hline VR & 0.534 & 0.234 & 0.596 & 0.248 & 0.481 & 0.385 \\
\hline
\end{tabular}

Note: This table reports hedging effectiveness of time-varying MV hedge ratios based on the bivariate GARCH models where transaction cost is taken into account for returns of the hedged portfolios. Maximal trading fee for the CSI300 index futures contracts is considered in the calculation. P1 refers to the sample period running from January 1, 2012 to November 16, 2019. P2 refers to the sample period running from November 17, 2019 to September 30, 2020. The starting dates of P1 for the influenza, facemask, coronavirus detection and disinfectant index vary across. For each sample period, $60 \%$ of the sample is used to estimate the GARCH models and the rest $40 \%$ of the sample is used to forecast the time-varying hedging ratios and their hedging effectiveness. CCC, constant conditional correlation model; DCC, dynamic conditional correlation model; ADCC, asymmetric dynamic conditional correlation model. VR, variance reduction. CSI300 IF is the CSI300 index futures. 
However, analysing the effects of the COVID-19 pandemic during P2, the constant OLS and EC strategies outperform the CCC strategy given the higher variance reduction offered by the former.

Further comparisons are made as to cross-hedging over the COVID concept-based stock indices. Considering the coronavirus and coronavirus detection indices to be hedged against, the constant Naïve or ROLS strategies perform better than the time-varying counterparts in the P1 period. The choice changes to the time-varying ADCC or CCC GARCH hedging strategies in the P2 period. To hedge against the influenza index, the best strategy remains the time-varying GARCH strategies with the CCC model for P1 and the ADCC model for P2. A third observation is that to hedge against the facemask and disinfectant indices, the best choice remains the constant strategies with the Naïve or OLS strategies in P1. In P2, to hedge against the same indices, the best choice is the OLS strategy for the disinfectant index while the Naïve strategy for the facemask index. In sum, it is found that the COVID-19 pandemic affects the choice of the best hedging strategy where the choice also varies across the stock indices to be hedged against. Using only one strategy over time is found to be sub-optimal.

\section{Conclusion}

Since the first case of COVID-19 was detected in China in November 2019, this fatal and highly infectious respiratory virus began to significantly impact the financial system both locally and globally. In this paper, we focus on the question of whether the Chinese index futures market acted as an effective tool to hedge risk in Chinese stock markets, particularly during the COVID-19 pandemic. Specifically, we examine the effectiveness of the CSI300 stock index futures to hedge against risks to the underlying CSI300 spot index as well as five COVID-19 concept-based stock index portfolios. The results of hedging against the COVID related stock indices consider whether the major stock market derivatives in China are an efficient tool to protect local investors from financial volatility and instability brought about by a critical public health disaster. We also revisit a debate on whether time-varying hedge ratios outperform constant hedge ratios in terms of hedging effectiveness by examining the hedging effectiveness of two types of hedging strategies and track any changes that occur between the pre- and post-COVID-19 periods. Results from this paper contribute to the literature through the identification of the direct effects of the COVID-19 pandemic on the functionality of the Chinese stock index futures and also provide important implications about significant shocks affecting the economy that should be noted by both local and foreign investors in the Chinese stock market.

To address our main question, we use naïve, OLS and EC/ROLS hedging strategies to represent constant hedge ratios. Results indicate that hedging over the CSI300 spot index shows that the outbreak of the COVID-19 pandemic decreased the effectiveness of the naïve strategy only moderately in terms of variance reduction. However, it increased the effectiveness of both the OLS and EC hedge ratios. The CSI300 index futures achieve variance reduction of approximately $49 \%$ to $61 \%$ when hedging over the five COVID related stock indices in the period before COVID-19. Effectiveness declines by approximately $11 \%$ to $45 \%$ as the COVID- 19 pandemic occurs. For the time-varying hedge ratios, we use CCC-, DCC- and ADCC-GARCH models for estimation. The result of hedging the CSI300 spot index suggest that COVID-19 weakens the effectiveness, which is substantial for the DCC- and ADCC-based hedge ratios. Time-varying cross-hedging over the COVID related stock index portfolios is also affected by COVID- 19 by between $20 \%$ and $40 \%$ in terms of variance reduction. The effectiveness of time-varying hedge ratios is retained when transaction costs are accounted for. The COVID-19 pandemic directly influenced the effectiveness of hedging and cross-hedging when considering the CSI300 index futures. Considering direct hedging, the effect is mostly positive for constant hedge ratios, whereas the effect is adverse for time-varying hedge ratios. However, the ability of the CSI300 index futures to hedge against the risks of COVID-19 is reduced regardless of whether a constant or time-varying hedge strategy is selected.

However, the optimal hedging strategy is identified to be the DCC-GARCH-based time-varying hedge ratio, which is identified to best hedge against the CSI300 spot index pre-COVID-19, while during the COVID-19 pandemic, OLS or EC constant strategies dominate. Focusing on cross-hedging procedures over the coronavirus index, a transition from the naïve strategy to the CCC-GARCH strategy when transitioning between the pre- to post-COVID-19 period performs optimally, with the results holding even when transaction costs are considered. Finally, the results presented here strongly suggest that the optimal hedging strategy will vary over time, and across hedged assets, especially when an economy faced a significant shock as was evidenced by the recent COVID-19 pandemic.

\section{References}

Akhtaruzzaman, M., Sensoy, A., Corbet, S., 2020. The influence of bitcoin on portfolio diversification and design. Finance Res. Lett. 37.

Akyildirim, E., Corbet, S., Cumming, D., Lucey, B., Sensoy, A., 2020. Riding the wave of crypto-exuberance: the potential misusage of corporate blockchain announcements. Technol. Forecast. Soc. Change 159.

Akyildirim, E., Corbet, S., Sensoy, A., Yarovaya, L., 2020. The impact of blockchain related name changes on corporate performance. J. Corp. Finance 65. Allen, F., Qian, Y., Tu, G., Yu, F., 2019. Entrusted loans: a close look at china's shadow banking system. J. Financ. Econ. 133 (1), $18-41$.

Ashraf, B., 2020. Stock markets' reaction to COVID-19: cases or fatalities? Res. Int. Bus. Finance 54.

Baillie, R.T., Bollerslev, T., 2002. The message in daily exchange rates: a conditional-variance tale. J. Bus. Econ. Stat. 20 (1), $60-68$.

Baillie, R.T., Han, Y.-W., Myers, R.J., Song, J., 2007. Long memory models for daily and high frequency commodity futures returns. J. Futures Mark. 27 (7), 643-668.

Baillie, R.T., Myers, R.J., 1991. Bivariate garch estimation of the optimal commodity futures hedge. J. Appl. Econom. 6 (2), $109-124$.

Basher, S.A., Sadorsky, P., 2016. Hedging emerging market stock prices with oil, gold, vix, and bonds: a comparison between dcc, adcc and go-garch. Energy Econ. 54, $235-247$.

Bauwens, L., Laurent, S., 2005. A new class of multivariate skew densities, with application to generalized autoregressive conditional heteroscedasticity models. J. Bus. Econ. Stat. 23 (3), 346-354.

Belhassine, O., 2020. Volatility spillovers and hedging effectiveness between the oil market and eurozone sectors: a tale of two crises. Res. Int. Bus. Finance 101195. 
Benet, B.A., 1992. Hedge period length and ex-ante futures hedging effectiveness: the case of foreign-exchange risk cross hedges. J. Futures Mark. (1986-1998) 43 (1), 163.

Bera, A.K., Garcia, P., Roh, J.-S., 1997. Estimation of time-varying hedge ratios for corn and soybeans: bgarch and random coefficient approaches. Sankhyā: Indian J. Stat. B 346-368.

Bollerslev, T., 1986. Generalized autoregressive conditional heteroskedasticity. J. Econom. 31 (3), 307-327.

Bollerslev, T., 1987. A conditionally heteroskedastic time series model for speculative prices and rates of return. Rev. Econ. Stat. $542-547$.

Bollerslev, T., 1990. Modelling the coherence in short-run nominal exchange rates: a multivariate generalized arch model. Rev. Econ. Stat. $498-505$.

Brooks, C., Cerny, A., Miffre, J., 2012. Optimal hedging with higher moments. J. Futures Mark. 32 (10), $909-944$.

Brooks, C., Henry, O.T., Persand, G., 2002. The effect of asymmetries on optimal hedge ratios. J. Bus. 75 (2), 333-352.

Cao, Z., Harris, R.D., Shen, J., 2010. Hedging and value at risk: a semi-parametric approach. J. Futures Mark. 30 (8), $780-794$.

Cappiello, L., Engle, R.F., Sheppard, K., 2006. Asymmetric dynamics in the correlations of global equity and bond returns. J. Financ. Econom. 4 (4), 537-572.

Cecchetti, S.G., Cumby, R.E., Figlewski, S., 1988. Estimation of the optimal futures hedge. Rev. Econ. Stat. 623-630.

Chen, S.-S., Lee, C.-F., Shrestha, K., 2004. An empirical analysis of the relationship between the hedge ratio and hedging horizon: a simultaneous estimation of the short-and long-run hedge ratios. J. Futures Mark. 24 (4), 359-386.

Cioroianu, I., Corbet, S., Larkin, C., 2020a. The differential impact of corporate blockchain-development as conditioned by sentiment and financial desperation. J. Corp. Finance 101814.

Cioroianu, I., Corbet, S., Larkin, C., 2020b. Guilt through association: reputational contagion and the boeing 737-max disasters. Econ. Lett.

Collins, R.A., 2000. The risk management effectiveness of multivariate hedging models in the us soy complex. J. Futures Mark. 20 (2), $189-204$.

Conlon, T., Corbet, S., McGee, R.J., 2020. Are cryptocurrencies a safe haven for equity markets?. an international perspective from the COVID-19 pandemic. Res. Int. Bus. Finance 101248.

Corbet, S., Goodell, J., Günay, S., 2020. Co-movements and spillovers of oil and renewable firms under extreme conditions: new evidence from negative wti prices during COVID-19. Energy Econ. 92.

Corbet, S., Hou, G., Hu, Y., Larkin, C.J., Oxley, L., 2020. Any port in a storm: cryptocurrency safe-havens during the COVID-19 pandemic. Econ. Lett. $194,109377$.

Corbet, S., Hou, G., Hu, Y., Oxley, L., 2020. The influence of the COVID-19 pandemic on asset-price discovery: testing the case of chinese informational asymmetry. Int. Rev. Financial Anal. 72, 101560.

Corbet, S., Hou, G., Hu, Y., Oxley, L., Xu, D., 2020. Pandemic-related financial market volatility spillovers: evidence from the chinese COVID-19 epicentre. Int. Rev. Econ. Finance 71, 55-81.

Corbet, S., Hou, Y., Hu, Y., Lucey, B., Oxley, L., 2020. Aye corona! [the] contagion effects of being named [corona] during the COVID-19 pandemic. Finance Res. Lett. 101591.

Corbet, S., Larkin, C., Lucey, B., 2020. ThCOVID-19f the COVID-19 pandemic: evidence from gold and cryptocurrencies. Finance Res. Lett. 101554.

Corbet, S., Lucey, B., Urquhart, A., Yarovaya, L., 2019. Cryptocurrencies as a financial asset: a systematic analysis. Int. Rev. Financial Anal. 62, 182-199.

Cotter, J., Hanly, J., 2006. Reevaluating hedging performance. J. Futures Mark. 26 (7), 677-702.

da Hsiang, D.L., 1996. The effect of the cointegration relationship on futures hedging: a note. J. Futures Mark. 16 (7), 773.

David, S., Inácio, J., Tenreiro Machado, J., 2021. The recovery of global stock markets indices after impacts due to pandemics. Res. Int. Bus. Finance 55.

Del Brio, E.B., Mora-Valencia, A., Perote, J., 2017. The kidnapping of europe: high-order moments' transmission between developed and emerging markets. Emerg. Mark. Rev. 31, 96-115.

Del Brio, E.B., Ñíguez, T.-M., Perote, J., 2011. Multivariate semi-nonparametric distributions with dynamic conditional correlations. Int. J. Forecast. 27 (2), $347-364$. Demirer, R., Lien, D., 2003. Downside risk for short and long hedgers. Int. Rev. Econ. Finance 12 (1), 25-44.

Ederington, L.H., 1979. The hedging performance of the new futures markets. J. Finance 34 (1), 157-170.

Engle, R., 2002. Dynamic conditional correlation: a simple class of multivariate generalized autoregressive conditional heteroskedasticity models. J. Bus. Econ. Stat. 20 (3), 339-350.

Engle, R.F., 1982. Autoregressive conditional heteroscedasticity with estimates of the variance of united kingdom inflation. Econometrica $987-1007$.

Engle, R.F., Gonzalez-Rivera, G., 1991. Semiparametric arch models. J. Bus. Econ. Stat. 9 (4), 345-359.

Engle, R.F., Kroner, K.F., 1995. Multivariate simultaneous generalized arch. Economet. Theor. 122-150.

Fan, J.H., Roca, E., Akimov, A., 2014. Estimation and performance evaluation of optimal hedge ratios in the carbon market of the european union emissions trading scheme. Aust. J. Manag. 39 (1), 73-91.

Fan, R., Li, H., Park, S.Y., 2016. Estimation and hedging effectiveness of time-varying hedge ratio: Nonparametric approaches. J. Futures Mark. 36 (10), 968-991. Ghosh, A., 1993. Hedging with stock index futures: estimation and forecasting with error correction model. J. Futures Mark. 13 (7), 743.

Ghosh, A., 1995. The hedging effectiveness of ecu futures contracts: forecasting evidence from an error correction model. Financ. Rev. 30 (3), $567-581$.

Ghosh, A., Clayton, R., 1996. Hedging with international stock index futures: an intertemporal error correction model. J. Financ. Res. 19 (4), $477-491$.

Gilbert, S., Jones, S.K., Morris, G.H., 2006. The impact of skewness in the hedging decision. J. Futures Mark. 26 (5), 503-520.

Goodell, J., 2020. COVID-19 and finance: agendas for future research. Finance Res. Lett. 35.

Goodell, J., Goutte, S., 2020. Co-movement of COVID-19 and bitcoin: evidence from wavelet coherence analysis. Finance Res. Lett.

Goodell, J., Huynh, T., 2020. Did congress trade ahead?. considering the reaction of us industries to COVID-19. Finance Res. Lett. 36.

Goutte, S., Péran, T., Porcher, T., 2020. The role of economic structural factors in determining pandemic mortality rates: evidence from the COVID-19 outbreak in france. Res. Int. Bus. Finance 54.

Harris, R.D., Shen, J., 2006. Hedging and value at risk. J. Futures Mark. 26 (4), 369-390.

Hill, J., Schneeweis, T., 1981. A note on the hedging effectiveness of foreign currency futures. J. Futures Mark. (pre-1986) 1 (4), 659.

Hill, J., Schneeweis, T., 1982. The hedging effectiveness of foreign currency futures. J. Financ. Res. 5 (1), 95-104.

Hou, Y., Holmes, M., 2020. Do higher order moments of return distribution provide better decisions in minimum-variance hedging?. evidence from us stock index futures. Aust. J. Manag. 45 (2), 240-265.

Hou, Y., Li, S., 2013. Hedging performance of chinese stock index futures: an empirical analysis using wavelet analysis and flexible bivariate garch approaches. PacBasin Financ J. 24, 109-131.

Hu, Y., Hou, Y., Oxley, L., Corbet, S., 2020. Does blockchain patent-development influence bitcoin risk? Journal of International Financial Markets, Institutions and Money.

Johnson, L.L., 1976. The theory of hedging and speculation in commodity futures. In The Economics of Futures Trading. Springer, pp. 83-99.

Junttila, J., Pesonen, J., Raatikainen, J., 2018. Commodity market based hedging against stock market risk in times of financial crisis: the case of crude oil and gold. J. Int. Financial Mark. Inst. Money 56, 255-280.

Katsiampa, P., Corbet, S., Lucey, B., 2019a. High frequency volatility co-movements in cryptocurrency markets. J. Int. Financial Mark. Inst. Money 62, 35-52.

Katsiampa, P., Corbet, S., Lucey, B., 2019b. Volatility spillover effects in leading cryptocurrencies: a bekk-mgarch analysis. Finance Res. Lett. $29,68-74$.

Kim, M.J., Park, S.Y., 2016. Optimal conditional hedge ratio: a simple shrinkage estimation approach. J. Empir. Finance 38, $139-156$.

Kroner, K.F., Sultan, J., 1993. Time-varying distributions and dynamic hedging with foreign currency futures. J. Financial Quant. Anal. 535-551.

Lai, Y.-S., Sheu, H.-J., 2010. The incremental value of a futures hedge using realized volatility. J. Futures Mark. 30 (9), $874-896$.

Lien, D., Shrestha, K., 2007. An empirical analysis of the relationship between hedge ratio and hedging horizon using wavelet analysis. J. Futures Mark. 27 (2), 127-150.

Lien, D., Tse, Y.K., 2002. Some recent developments in futures hedging. J. Econ. Surv. 16 (3), 357-396.

Lin, B., Su, T., 2021. Does COVID-19 open a pandora's box of changing the connectedness in energy commodities? Res. Int. Bus. Finance 56.

Liu, J., Stambaugh, R.F., Yuan, Y., 2019. Size and value in china. J. Financ. Econ. 134 (1), $48-69$. 
Maghyereh, A.I., Awartani, B., Tziogkidis, P., 2017. Volatility spillovers and cross-hedging between gold, oil and equities: evidence from the gulf cooperation council countries. Energy Econ. 68, 440-453.

Malliaris, A.G., Urrutia, J.L., et al., 1991. The impact of the lengths of estimation periods and hedging horizons on the effectiveness of a hedge: evidence from foreign currency futures. J. Futures Mark. 11 (3), 271-289.

Markopoulou, C.E., Skintzi, V.D., Refenes, A.-P.N., 2016. Realized hedge ratio: predictability and hedging performance. Int. Rev. Financial Anal. 45, 121-133.

McIver, R., Kang, S., 2020. Financial crises and the dynamics of the spillovers between the u.s. and brics stock markets. Res. Int. Bus. Finance 54.

Meegan, A., Corbet, S., Larkin, C., 2018. Financial market spillovers during the quantitative easing programmes of the global financial crisis (2007-2009) and the european debt crisis. J. Int. Financial Mark. Inst. Money 56, 128-148.

Nelson, D.B., 1991. Conditional heteroskedasticity in asset returns: a new approach. Econometrica 347-370.

Ñíguez, T.-M., Perote, J., 2016. Multivariate moments expansion density: application of the dynamic equicorrelation model. J. Bank. Financ. 72, S216-S232.

Park, S.Y., Jei, S.Y., 2010. Estimation and hedging effectiveness of time-varying hedge ratio: flexible bivariate garch approaches. J. Futures Mark. 30 (1), 71-99.

Park, T.H., Switzer, L.N., 1995. Bivariate garch estimation of the optimal hedge ratios for stock index futures: a note. J. Futures Mark. 15 (1), 61.

Popkova, E., DeLo, P., Sergi, B., 2021. Corporate social responsibility amid social distancing during the COVID-19 crisis: brics vs. oecd countries. Res. Int. Bus. Finance 55.

Qu, H., Wang, T., Zhang, Y., Sun, P., 2019. Dynamic hedging using the realized minimum-variance hedge ratio approach-examination of the csi 300 index futures. Pac-Basin Finance J. 57, 101048.

Seven, Yilmaz, F., 2021. World equity markets and COVID-19: immediate response and recovery prospects. Res. Int. Bus. Finance 56.

Stein, J.L., 1976. The simultaneous determination of spot and futures prices. The Economics of Futures Trading. Springer, pp. $124-130$.

Tang, C.-H., Chin, C.-Y., Lee, Y.-H., 2021. Coronavirus disease outbreak and supply chain disruption: evidence from taiwanese firms in china. Res. Int. Bus. Finance 56.

Tse, Y.K., Tsui, A.K.C., 2002. A multivariate generalized autoregressive conditional heteroscedasticity model with time-varying correlations. J. Bus. Econ. Stat. 20 (3), $351-362$.

Wei, Y., Wang, Y., Huang, D., 2011. A copula-multifractal volatility hedging model for csi 300 index futures. Physica A 390 (23-24), 4260-4272.

Yan, Z., Li, S., 2018. Hedge ratio on markov regime-switching diagonal bekk-garch model. Finance Res. Lett. 24, 49-55. 